\title{
Field assessment of a pulse width modulation (PWM) spray system applying different spray volumes: duty cycle and forward speed effects on vines spray coverage
}

\author{
Marco Grella ${ }^{1}$ (D) Fabrizio Gioelli ${ }^{1} \cdot$ Paolo Marucco $^{1} \cdot$ Ingrid Zwertvaegher $^{2}$. \\ Eric Mozzanini ${ }^{1} \cdot$ Nikolaos Mylonas $^{3} \cdot$ David Nuyttens $^{2} \cdot$ Paolo Balsari $^{1}$
}

Accepted: 4 August 2021 / Published online: 14 August 2021

(C) The Author(s) 2021

\begin{abstract}
The pulse width modulation (PWM) spray system is the most advanced technology to obtain variable rate spray application without varying the operative sprayer parameters (e.g. spray pressure, nozzle size). According to the precision agriculture principles, PWM is the prime technology that allows to spray the required amount where needed without varying the droplet size spectra which benefits both the uniformity of spray quality and the spray drift reduction. However, some concerns related to the effect of on-off solenoid valves and the alternating on/off action of adjacent nozzles on final uneven spray coverage (SC) have arisen. Further evaluations of PWM systems used for spraying 3D crops under field conditions are welcomed. A tower-shaped airblast sprayer equipped with a PWM was tested in a vineyard. Twelve configurations, combining duty cycles (DC: 30, 50, 70, 100\%) and forward speeds (FS: 4, 6, $8 \mathrm{~km} \mathrm{~h}^{-1}$ ), were tested. Two methodologies, namely fieldstandardized and real field conditions, were adopted to evaluate the effect of DC and FS on (1) SC variability (CV\%) along both the sprayer travel direction and the vertical spray profile using long water sensitive papers (WSP), and (2) SC uniformity ( $\mathrm{I}_{\mathrm{U}}$, index value) within the canopy at different depths and heights, respectively. Furthermore, the SC (\%) and deposit density (Nst, no stains $\mathrm{cm}^{-2}$ ), determined using short WSP, were used to evaluate the spray application performances taking into account the spray volumes applied. Under field-controlled conditions, the pulsing of the PWM system affects both the SC variability measured along the sprayer travel direction and along the vertical spray profile. In contrast, under real field conditions, the PWM system does not affect the uniformity of SC measured within the canopy. The relationship between $\mathrm{SC}$ and $\mathrm{N}_{\mathrm{st}}$ allowed identification of the ranges of 200-250 and 300-370 $1 \mathrm{ha}^{-1}$ as the most suitable spray volumes to be applied for insecticide and fungicide plant protection products, respectively.
\end{abstract}

Keywords Spray application technology $\cdot$ Coverage variability $\cdot$ Deposit density $\cdot$ Spray volume $\cdot$ Application efficiency $\cdot$ Droplet size spectra

Marco Grella

marco.grella@unito.it

Extended author information available on the last page of the article 


\section{Abbreviations}

$\mathrm{CV} \quad$ Variability of spray coverage expressed as coefficient of variation (\%)

DC Duty cycle (\%)

Dlev Canopy depth levels, namely external and internal portions

FS Forward speed $\left(\mathrm{m} \mathrm{s}^{-1}\right)$

$\mathrm{I}_{\mathrm{U}} \quad$ Uniformity Index (Index Value)

Hlev Canopy height levels, namely bottom, middle and top portions

LP Water sensitive paper line position within the frame used to hold it

$\mathrm{N}_{\mathrm{st}} \quad$ Deposit density averaged over leaf sides expressed as number of stains per unit area $\left(\mathrm{cm}^{2}\right)$

$\mathrm{N}_{\text {st-lo }} \quad$ Deposit density at the lower leaf side expressed as number of stains per unit area $\left(\mathrm{cm}^{2}\right)$

$\mathrm{N}_{\text {st-up }} \quad$ Deposit density at the upper leaf side expressed as number of stains per unit area $\left(\mathrm{cm}^{2}\right)$

PWM Pulse width modulation

SC Spray coverage averaged over leaf sides (\%)

$\mathrm{SC}_{\mathrm{lo}} \quad$ Spray coverage at the lower leaf side (\%)

$\mathrm{SC}_{\text {up }} \quad$ Spray coverage at the upper leaf side (\%)

WSP Water sensitive paper

\section{Introduction}

The European Green Deal, and more specifically the Farm to Fork Strategy, strives to reduce the overall use of agrochemicals by $50 \%$ by 2030 (EC, 2020). In this respect, the European Commission will enhance the implementation of Integrated Pest Management (IPM). Besides alternative control strategies, such as crop rotation and mechanical weeding, precision spraying techniques can help to achieve this goal.

A perfect spraying system ultimately aims to deliver and deposit a precise amount of active ingredient uniformly and exclusively upon a target area. Ideally, only the exact (minimum) amount of product required to achieve the desired biological effect would be released and all product discharged from the sprayer would reach the desired target (Giles \& Comino, 1989). Achieving this goal is extremely challenging for agricultural spray applications; nevertheless, pesticide losses, under- and over-application, as well as inadequate coverage and deposition, should be avoided as much as possible to safeguard the environment, food safety and human health.

Conventional spray applications generally apply agrochemicals at a constant rate $\left(1 \mathrm{ha}^{-1}\right)$ throughout the field, irrespective of pest/disease presence, planting system, crop density or tree canopy characteristics, which contribute to a lower application efficiency. In vineyards, orchards and other fruit productions high variability within and between trees in foliage density, canopy shape and size, typically results in trees being over- or under-sprayed when using a constant rate application (Chen et al., 2019; Salcedo et al., 2020; Zhu et al., 2008).

The quality of pesticide application can potentially be improved by accurately determining the spray rate based on the canopy structure and enhancing the accuracy of the spray rate (Campos et al., 2020; Miranda-Fuentes et al., 2015). Indeed, variable-rate sprayers, which adjust the application rates using flow controllers based on information from realtime or sensor-guided canopy detection systems (e.g. ultrasonic, infrared, light detection and ranging-LIDAR, and stereo vision sensors) (Balsari et al., 2009; Berk et al., 2016; 
Comba et al., 2019; Palleja \& Landers, 2015; Zhang et al., 2018), have been shown to improve spray application efficiency and reduce off-target losses (Cai et al., 2019; Chen et al., 2019; Gil et al., 2007; Jeon \& Zhu, 2012; Llorens et al., 2010).

Variable rates can be achieved through pressure-based systems, injection systems, or pulse width modulation (PWM) systems. Pressure-based systems have been shown to have a slow response time and affect nozzle performance, specifically droplet size and spray distribution (Giles \& Comino, 1989). Similarly, direct injection systems that inject the active ingredient upstream of the nozzle, were reported to show application errors caused by lag effects (Anglund \& Ayers, 2003). The PWM technology controls the nozzle flow rate by pulsing an electronically-actuated solenoid valve directly upstream of the nozzle. The flow is changed by controlling the relative proportion of time each solenoid valve is open (duty cycle). The system therefore allows real-time flow rate changes while maintaining the operating pressure (Butts et al., 2019). The effects of PWM flow control on droplet sizes and velocities were found to be relatively minor, especially compared to pressure-based systems (Giles, 2020; Giles \& Ben-Salem, 1992; Giles \& Comino, 1990; Giles et al., 2002; Gopala Pillai et al., 1999).

For this reason, PWM technology that allows control of spray droplet size and flow rate of each nozzle independently has been extensively used in the development of innovative variable rate sprayers in accordance with the precision agriculture principles to spray only where and how much is needed. This technology has lead to promising results in reducing both chemical inputs and spray drift. For example, Salcedo et al. (2020) reported more than $65 \%$ spray volume reduction with a laser-guided PWM-controlled variable rate air-blast orchard sprayer compared to a constant rate application with the same sprayer (by disabling the PWM control system) in two-year old apple trees, while still providing sufficient spray deposits and coverage for effective fungicide and insecticide applications (proposed by pesticide manufacturers) without over-application. Furthermore, in this study, it was proven that the use of PWM solenoid valves improved distribution uniformities of both spray deposition and coverage. Previously, Chen et al. (2013) found similar results.

Despite promising results, concerns still exist regarding the spray coverage accuracy and uniformity with the PWM system due to the solenoid on/off latency and the alternating on/off action of adjacent nozzles in some systems. Mangus et al. (2017) identified through lab based simulation that, although an accurate flow rate was emitted per pulse (regardless of duty cycle and number of nozzles activated), spray coverage accuracy decreased as duty cycle decreased, meaning lower duty cycles resulted in a lower percentage of area receiving the target application rate, and thus in more under- or over-application. In the early stages of PWM technology development, Giles and Comino (1990) found that a reduction in duty cycle resulted in spray distribution patterns with significantly more spray deposit directly underneath the nozzles and reductions in the outer regions of the pattern. The distortion was relatively minor for the tested flat-fan nozzles and severe for the solid-cone nozzles. Although several authors have recently studied the effect of PWM on droplet size spectra, activation pressure and flow rate at different duty cycles with different nozzle types (Butts et al., 2018, 2019; Deng et al., 2020; Llorens \& Hewitt, 2019; Wei et al., 2020), very few studies on the use of PWM in field conditions are available in the literature, especially for 3D crops, where the interest for the PWM system for variable rate applications increases daily. Therefore, more studies in real field conditions are needed to better understand the efficacy of PWM systems in applying chemicals to valuable, widespread crops, such as vineyards and orchards.

The objective of this study was to test the effect of PWM duty cycle and sprayer forward speed on the spray coverage variability (i) along the sprayer track and canopy height at the 
edge of the canopy using long water sensitive papers (WSP; plot L), and (ii) along the canopy height and canopy depth using short WSPs (plot S) in a 11 years old vineyard at full growth stage. Contextually, an estimation of the most suitable spray volume to obtain an efficient spray application that minimizes overspray and maximizes the potential efficacy of plant protection products was also carried out.

\section{Materials and methods}

\section{Droplet size and velocity characteristics}

Preliminary tests were conducted to determine the effect of PWM duty cycle and the presence of a solenoid valve on the spray droplet size and velocity characteristics. Laboratory trials were conducted at the ILVO Spray Technology Lab using the DynaJet@ Flex 7140 PWM system at the default setting of $20 \mathrm{~Hz}$ (TeeJet, Spraying Systems Co., Wheaton, Illinois USA). Measurements were performed using a Phase Doppler Particle Analyser (PDPA), as described by Nuyttens et al. (2007). The PDPA laser used was an Aerometrics PDPA one dimensional system (TSI, Minneapolis, USA). When a droplet passes through a small sampling volume, formed by two intersecting laser beams, light is scattered by refraction. From the light scattering characteristics, droplet sizes and velocities are obtained. Measurements were carried out with the standard flat fan nozzle XR8002 VS (TeeJet, Spraying Systems Co., Wheaton, Illinois USA) at 4 duty cycle settings (30\%, 50\%, $70 \%, 100 \%$ ) at $0.40 \mathrm{MPa}$ and at a distance of $0.5 \mathrm{~m}$ below the nozzle. Tests were carried out without air support using a single nozzle set-up, and were repeated three times.

\section{Sprayer characteristics and configurations tested in field trials}

A prototype vineyard sprayer developed in the ambit of the H2020 OPTIMA project (http://optima-h2020.eu/), i.e. Smart Synthesis (Caffini S.p.a., Palù, Verona, Italy), was employed. It is a trailed sprayer with a 10001 polyethylene tank and an innovative axial fan with an electrical engine (KEB automation KG, Barntrup, Germany). The fan, $700 \mathrm{~mm}$ in diameter and consisting of nine blades, sucks in the air from the front of a tower shaped air conveyor (Fig. 1a). The latter is equipped with multiple adjustable deflectors placed internally at the edge of the air-jet outlet, thus allowing direction of the airflow to match the canopy height. An electric-control varies the orientation of the whole air conveyor with respect to the central axis of the air-jet discharge system backwards and forward, thus determining the incidence angle of both airflow and spray jets on the canopy. The sprayer was equipped with a DynaJet ${ }^{\circledR}$ Flex 7140 PWM system (TeeJet, Spraying Systems Co., Wheaton, Illinois, USA). On each side of the sprayer, a vertical boom was mounted to the air-conveyor, each containing eight PWM solenoid valves coupled with a single nozzle holder, placed at $180 \mathrm{~mm}$ spacing along the boom (Fig. 1b). The PWM valves varied the duty cycle of the pulse signals to change the spray outputs (at a frequency of $20 \mathrm{~Hz}$ ). The PWM system uses a blended pulse in which every other nozzle operates at an alternate frequency. So, below $50 \%$ DC, two adjacent nozzles can be off at the same time, resulting in no spray for very short periods of time (less than $25 \mathrm{~ms}$ at $20 \mathrm{~Hz}$ ) and thus possibly zones with no or low amounts of spray deposit resulting in a high variation in spray coverage. In this study, each trial was 
(a)

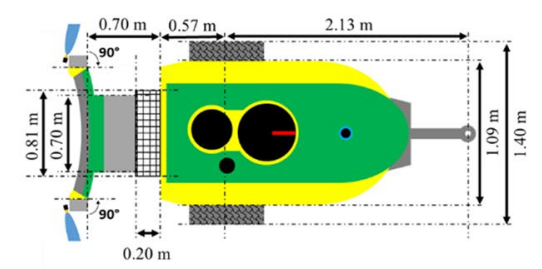

Draws not to scale.

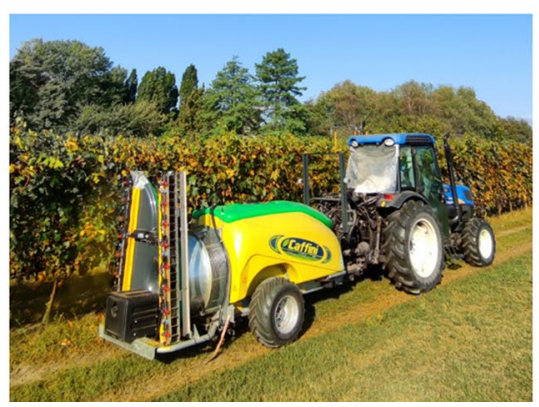

(b)
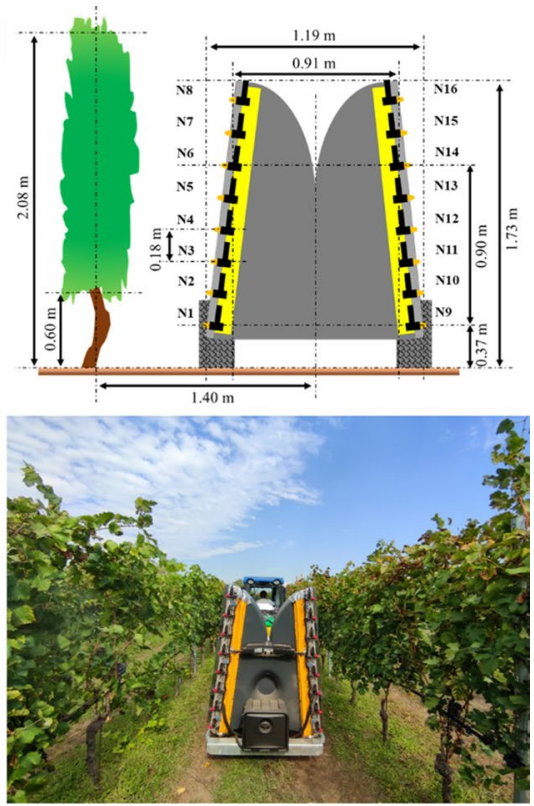

Fig. 1 Smart synthesis vineyard sprayer featured by tower shaped air-jet discharge system, axial fan with electrical engine, and PWM DynaJet ${ }^{\circledR}$ system controlling the sprayed liquid rate of 16 nozzles. a Aerial view and $\mathbf{b}$ back view. During the field trials the nozzles N7, N8, N15 and N16 were disabled

undertaken at a constant spray application rate by using a fixed duty cycle $(30 \%, 50 \%$, $70 \%, 100 \%$ ) which was manually set through a dedicated DynaJet control unit at the start of each trial.

The sprayer was equipped with standard flat fan nozzles XR8002 VS (TeeJet, Spraying Systems Co., Wheaton, Illinois USA). The trials were carried out at a working pressure of $0.40 \mathrm{MPa}$, corresponding to a nominal nozzle flow rate of $0.911 \mathrm{~min}^{-1}$. Based on a preliminary check of the vertical spray profile, considering an intended canopy target height of $2.0 \mathrm{~m}$, only the bottom six nozzles on each side of the sprayer were activated. The upper nozzles (N7, N8, N15, N16) were turned off (Fig. 1b). The internal air deflectors were adequately adjusted to match the canopy height and to minimize spray losses over the target height. All trials were conducted at a fixed fan revolution speed of 1600 rev $\min ^{-1}$, producing an average airflow of $17050 \mathrm{~m}^{3} \mathrm{~h}^{-1}$. The mean air velocity at the air outlet was $20.4 \mathrm{~m} \mathrm{~s}^{-1}$. The electric axial fan ensured a fixed and constant fan revolution speed, irrespective of the PTO revolution speed, throughout the duration of the trials. The air conveyor was placed orthogonal to the rows $\left(90^{\circ}\right.$ relative to the central axis of the air-jet discharge system) in all trials (Fig. 1a).

In total, twelve sprayer configurations, deriving from the combination of four PWM duty cycles $(30,50,70,100 \%)$ and three forward speeds $\left(4.0,6.0\right.$ and $8.0 \mathrm{~km} \mathrm{~h}^{-1}$ corresponding to $1.11,1.67$ and $2.22 \mathrm{~m} \mathrm{~s}^{-1}$, respectively) were tested resulting in spray application rates ranging from 87.8 up to $585.01 \mathrm{ha}^{-1}$. Three replicates were conducted for each configuration tested. The main variables examined are summarized in Table 1. The order in which configurations and replications were tested was fully-randomized using Excel software function. 
Table 1 Sprayer configurations tested with the smart synthesis vineyard sprayer using 12 active TeeJet XR 8002 VS nozzles at $0.4 \mathrm{MPa}$

\begin{tabular}{lcclc}
\hline ID unique & $\begin{array}{l}\text { PWM duty cycle } \\
(\%)\end{array}$ & $\begin{array}{l}\text { Tot. flow rate }(1 \\
\left.\mathrm{min}^{-1}\right)\end{array}$ & $\begin{array}{l}\text { Forward speed (m } \\
\left.\mathrm{s}^{-1}\right)\end{array}$ & $\begin{array}{l}\text { Applied volume }(1 \\
\left.\text { ha }^{-1} \text { of ground area }\right)\end{array}$ \\
\hline FS4_DC30 & 30 & 3.3 & 1.11 & 175.5 \\
FS4_DC50 & 50 & 5.5 & 1.11 & 292.5 \\
FS4_DC70 & 70 & 7.6 & 1.11 & 409.5 \\
FS4_DC100 & 100 & 10.9 & 1.11 & 585.0 \\
FS6_DC30 & 30 & 3.3 & 1.67 & 117.0 \\
FS6_DC50 & 50 & 5.5 & 1.67 & 195.0 \\
FS6_DC70 & 70 & 7.6 & 1.67 & 273.0 \\
FS6_DC100 & 100 & 10.9 & 1.67 & 390.0 \\
FS8_DC30 & 30 & 3.3 & 2.22 & 87.8 \\
FS8_DC50 & 50 & 5.5 & 2.22 & 146.3 \\
FS8_DC70 & 70 & 7.6 & 2.22 & 204.8 \\
FS8_DC100 & 100 & 10.9 & 2.22 & 292.5 \\
\hline
\end{tabular}

${ }^{a}$ ID unique is a unique combination composed of Forward Speed (FS4, FS6 and FS8 corresponding to 4, 6 and $8 \mathrm{~km} \mathrm{~h}^{-1}$, respectively) and Duty Cycle (DC30, DV50, DC70 and DC100 corresponding to 30, 40, 50 and $100 \%$, respectively)

\section{Field test location and vineyard characteristics}

In September 2020, field trials were carried out in an espalier-trained vineyard (cv: Barbera) at growth stage BBCH 89 "Berries ripe for harvest" (Lorenz et al., 1994) located at DiSAFA facilities in Grugliasco, Turin, Italy. The vine rows were $62 \mathrm{~m}$ long and oriented NW-SE (146 ${ }^{\circ}$ azimuth) (Fig. 2). Planting distances were $2.8 \mathrm{~m}$ between rows and $0.8 \mathrm{~m}$ within rows with a resulting density of 4464 vines $\mathrm{ha}^{-1}$. To accurately characterize the vineyard crop, the point quadrat technique (PQT) was used as described in detail by Grella et al. (2019) and Vitali et al. (2013). At six blocks, distributed in the first two rows (three blocks per row), and at four vine canopies per block, PQT measurements were taken in the vegetative strip at heights between 0.4 and $2.2 \mathrm{~m}$. The average vineyard height from the ground was $2.08 \mathrm{~m}$ with a vegetative strip of $1.48 \mathrm{~m}$ and a canopy width of $0.48 \mathrm{~m}$. The mean vegetative parameters were 2.2 leaf layers, $13.1 \%$ gaps, and a leaf area index (LAI) of 1.31, calculated according to Pergher and Petris (2008).

\section{Experimental plot layout and sampling system}

The trials were carried out in the two outermost rows of the vineyard. Along each of these rows, two test plots (L and S) were established (Fig. 2). Each plot was characterized by a total area of $174 \mathrm{~m}^{2}(31.0 \mathrm{~m} \times 5.6 \mathrm{~m})$.

The variability of spray coverage at the edge of the canopy along (i) the sprayer track and (ii) the canopy height was measured in plot L under field-standardized conditions by spraying only from one side of each row (Fig. 2). For this purpose, long strips of WSP (500 mm $\times 26 \mathrm{~mm}$, Syngenta Crop Protection AG, Basel, Switzerland) were used. Fieldstandardized conditions were obtained by avoiding interaction of the spray with the leaves, 


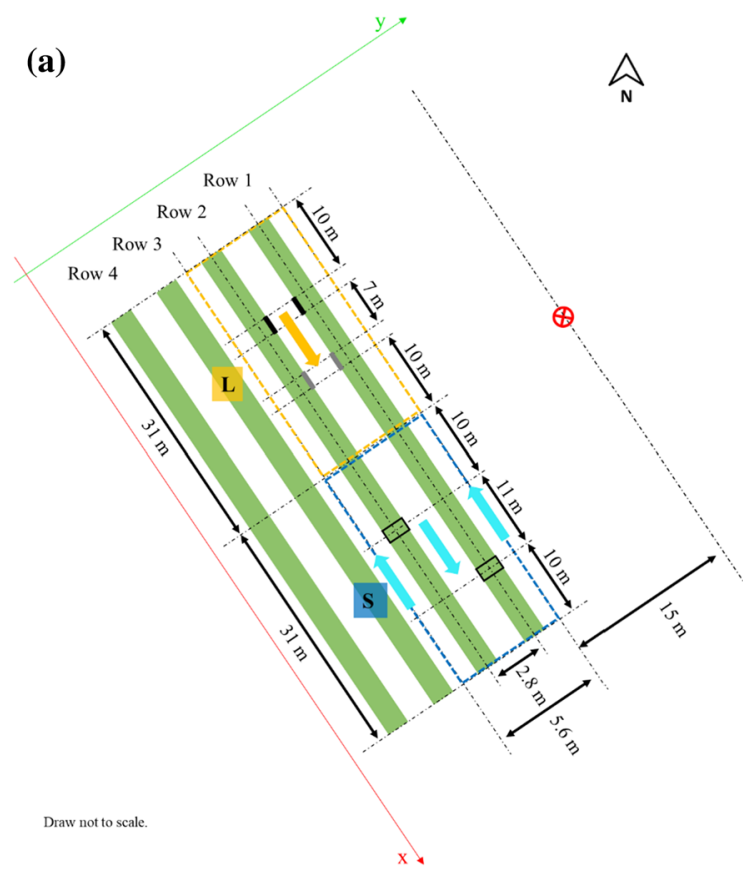
Test plot $\mathrm{L}$ for the measurement of coverage using longstrip WSP
$\Rightarrow$ Sprayer track used in L test plot (one side per row applied)
- Wooden structure used to hold the longstrip WSP in horizontal position
- Wooden structure used to hold the longstrip WSP in vertical position
Test plot $S$ for the measurement of coverage using short WSP
$\Longrightarrow$ Sprayer tracks used in S test plot (two rows completly applied)
$\square$ Selected canopies where the short WSPs were stapled at different locations
(8) Weather station

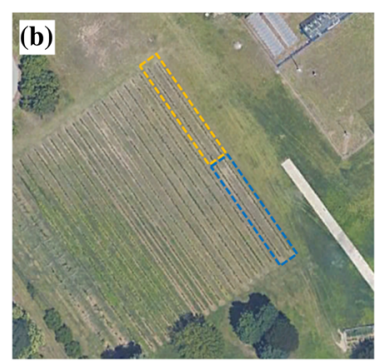

Fig. 2 a Schematic of trial layout for the spray coverage measurements in field-standardized conditions (plot L) and in real field conditions (plot S). b Aerial view of the vineyard field trial area

while still allowing interaction between the spray plume and the air-jet from the sprayer, as the latter influences the spray droplet trajectories. This was done to gain insight into the effect of the PWM system and alternating nozzles on the theoretical spray coverage with minimal interference of other factors. To evaluate the variability of spray coverage along the sprayer track, two ad hoc wooden frames held the long WSPs horizontally at three different heights, namely at $0.8 \mathrm{~m}$ (grapes band), $1.4 \mathrm{~m}$ (middle of the vegetation strip) and $2.0 \mathrm{~m}$ (top of the vegetation strip) from the ground (respectively H1, H2, and H3; Fig. $3 \mathrm{a}$ and $b$ ). To evaluate the variability of spray coverage along the canopy height, two additional wooden frames held long WSPs vertically from 0.5 to $2.0 \mathrm{~m}$ from the ground at three advancing distances each $1.0 \mathrm{~m}$ apart (respectively D1, D2, and D3; Fig. 3c and d). In each sampled position, namely at the three canopy heights and at the three distances along the row, three long WSPs were aligned next to each other in order to simulate a unique WSP collector of $1500 \mathrm{~mm}$ length with a total exposed surface of $390 \mathrm{~cm}^{2}$ (Fig. $3 \mathrm{a}$ and c). In both cases, one frame was placed on the right side of row 1 and the other on the left side of row 2 to evaluate the target coverage of the spray-jet generated by respectively the left and right side of the sprayer (Fig. $3 b$ and d). The frames were positioned at the edges of the canopy, thus avoiding interference with canopy leaves, and were maintained in the same position for all trials and replicates. The wooden frames were distributed in the test plot ensuring $7 \mathrm{~m}$ distance between the frames used to measure the variability of spray coverage along the sprayer track and those used to assess the variability along the canopy height. Per replicate, a single sprayer pass in the alley between row 1 and 2 was carried out by applying pure water (Fig. 2a).

The spray coverage inside the canopy was measured in plot $\mathrm{S}$ under real field conditions by spraying both sides of the rows (Fig. 2). Real field conditions were obtained by allowing 

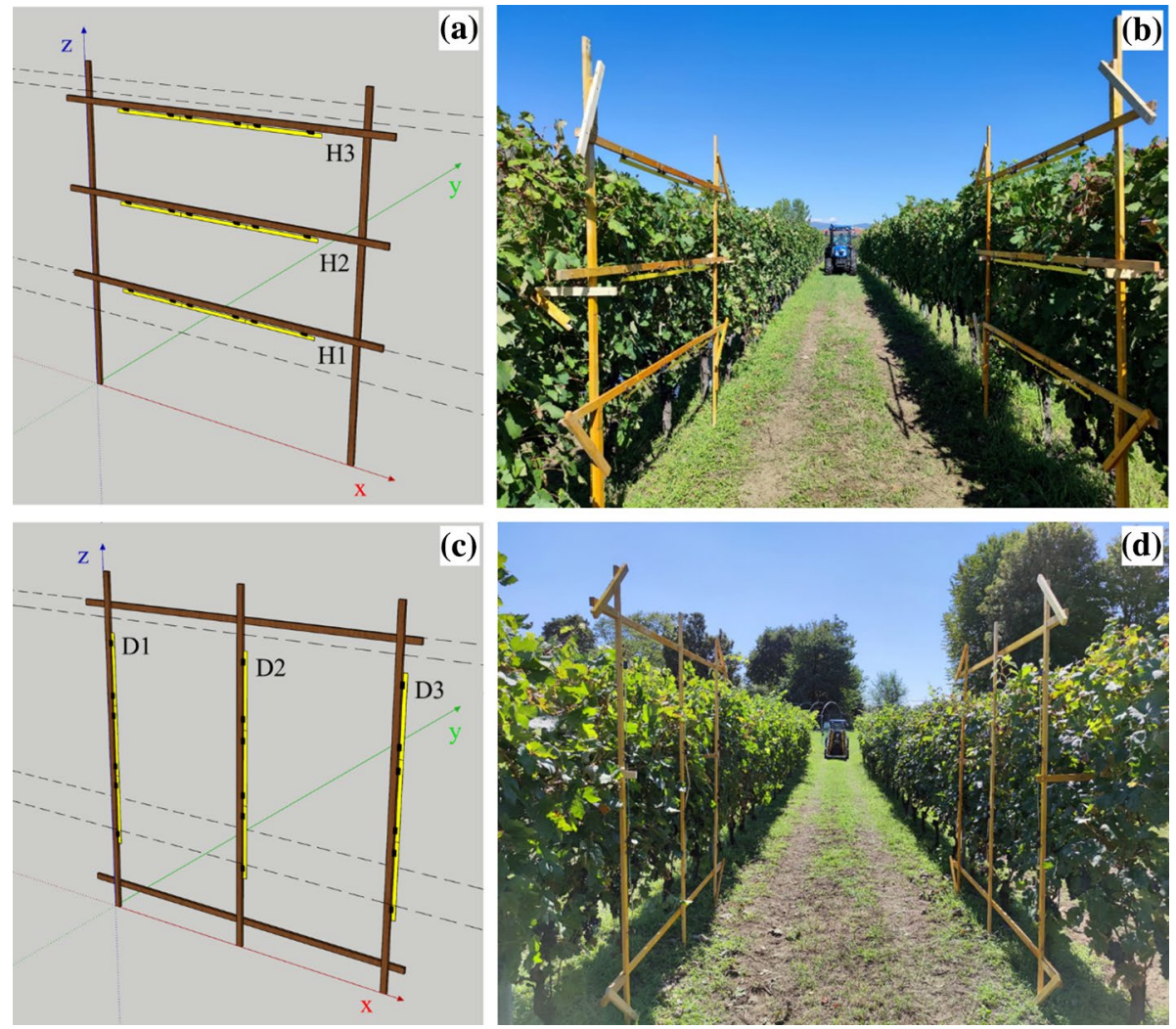

Fig. 3 Three-dimensional schematic and real-field sampling positions of the WSP lines for the evaluation of spray coverage homogeneity $\mathbf{a}, \mathbf{b}$ along the sprayer track at three heights $(\mathrm{H} 1, \mathrm{H} 2, \mathrm{H} 3)$ and $\mathbf{c}$, d along the canopy height at three advancing distances (D1, D2, D3). Each WSP line is composed of three long WSPs aligned and clipped to the wooden structure. The grey, dashed lines represent the tree row volume (Color figure online)

both interaction of the spray and the air-jet with the leaves. For this purpose, the sampling strategy described by Grella et al. (2020) was adopted. The spray coverage was assessed at nine sampling positions per vine arranged at three heights (1: bottom, 2: middle, 3: top) and three depths (A: right edge, B: middle, C: left edge). At each sampling location, two paired short WSPs $(76 \mathrm{~mm} \times 26 \mathrm{~mm}$, Syngenta Crop Protection AG, Basel, Switzerland), attached to the upper and lower leaf surface, were directly stapled to the leaf. In the process of selecting sample locations on real vines, the guidelines were to staple the WSP as close to the designated location as possible, given that there were leaves available for stapling. Where and when possible the WSPs were stapled to the same leaves. If not possible, the nearest leaves were selected. Within row 1 and 2, one canopy vine per row was sampled and the two sampled canopies were situated $11 \mathrm{~m}$ apart (Fig. 2a). The proposed sampling strategy is broadly used to assess leaf coverage under real conditions during spray application field trials (Hołownicki et al., 2002; Rincón et al., 2020; Salcedo et al., 2020; Salyani et al., 2013). 
The two plots were sprayed consecutively using pure water, meaning that the sprayer started the spray application in plot L in the alley between rows 1 and 2, and continued the application in plot $S$ without stopping, then the left side of row 1 and the right side of row 2 were sprayed in plot $S$ only (Fig. 2a). At the end of each spray application, the WSPs were collected, labelled using a unique code, and stored under controlled, dry conditions.

The environmental conditions were monitored over the full duration of the trials using a weather station placed $15 \mathrm{~m}$ away from the sprayed area in a crop free area, at the intersection of the test plots (Fig. 2a). The weather station was equipped with a sonic anemometer 232 (Campbell Scientific, Logan, UT, USA) at $4.0 \mathrm{~m}$ height to measure wind speed and direction relative to the spray track, and two thermo-hygrometer HC2S3 probes (Campbell Scientific) placed at 2.0 and $4.0 \mathrm{~m}$ heights to measure air temperature and relative humidity (RH). All measurements were taken at a frequency of $0.1 \mathrm{~Hz}$ and all data were recorded automatically by a data logger CR800 (Campbell Scientific). The mean air temperature was $22.8^{\circ} \mathrm{C}$, mean $\mathrm{RH}$ was $54.5 \%$, average wind speed recorded in each trial was always below $1.48 \mathrm{~m} \mathrm{~s}^{-1}$. The weather conditions accomplish the optimal conditions for spray application defined by the best management practices (BMPs) (TOPPS-Prowadis Project, 2014). In all cases, the trials were conducted in "light air" conditions (Barua, 2005), making the data derived from the different trials broadly comparable. The weather data recorded during the trials are shown for each configuration and replicate in Table 6 in appendix.

\section{Sample processing and WSP analysis}

Prior to the sample analysis, the long WSPs were cut into sections of $50 \mathrm{~mm}$ (ten sections per long WSP). Each collector line composed of three aligned long WSPs $(1500 \mathrm{~mm} \times$ $26 \mathrm{~mm}$ ) thus generated 30 sections (Fig. 12). From each collector line, the 30 WSP sections $\left(50 \mathrm{~mm} \times 26 \mathrm{~mm}, \mathrm{n}_{\text {tot }}=12,960\right)$ were then fixed on a single rigid support next to each other. The short WSPs $\left(76 \mathrm{~mm} \times 26 \mathrm{~mm}, \mathrm{n}_{\text {tot }}=1,296\right)$ were also fixed to a single rigid support. The WSPs were then scanned and images were produced at a resolution of $600 \mathrm{dpi}$ using a HP Color Laser Jet Pro MPF M479dw printer with integrated scanner (HP, Palo Alto, California, U.S.A.). A specially programmed image processing macro (MirandaFuentes et al., 2016; Zhu et al., 2011) in ImageJ (National Institutes of Health, Bethesda, MD, USA) (Rueden et al., 2017) was used to determine the spray coverage parameters. Spray coverage (\%) was calculated as the percentage area covered with the spray deposits on the WSP and deposits density (no stains $\mathrm{cm}^{-2}$ ) was determined as the number of spray deposit stains per unit of WSP target area (Cerruto et al., 2019).

\section{Data analysis}

All statistical analyses were performed using IBM SPSS Statistics (Version 26) predictive analytics software for Windows. The data were tested for normality using the Shapiro-Wilk test and by visual assessment of the Q-Q plots of Z-scores for both the spray coverage and deposits density. Residuals analyses were also performed. An Arcsin[...] transformation was used to achieve residual normality and homoscedasticity of data, expressed as percentage. The data derived from the two test plots were analysed separately. 
Regarding the long WSPs (plot L), the coefficient of variation $(\mathrm{CV}, \%)$ of the spray coverage was calculated per sampling position and used as indicator for variability of the spray coverage along the sprayer track $\left(\mathrm{CV}_{\text {sprayer track }}\right.$ for the horizontal lines) and along the canopy heights $\left(\mathrm{CV}_{\text {canopy height }}\right.$ for the vertical lines). A three-way analysis of variance (ANOVA) was used to establish the effect of the independent variables duty cycle (DC), forward speed (FS) and the position of the WSP sampling line (LP) on the dependent variables $\mathrm{CV}_{\text {sprayer track }}$ and $\mathrm{CV}_{\text {canopy height }}$.

A four-way ANOVA was used to test the effect of the independent variables DC, FS, canopy depth (Dlev) and canopy height (Hlev) on the dependent variables, spray coverage (SC, $\%$ ) and deposit density $\left(\mathrm{N}_{\mathrm{st}}\right.$, no of stains $\left.\mathrm{cm}^{-2}\right)$ obtained from the $\mathrm{S}$ plot. The dependent variables were considered separately for the upper $\left(\mathrm{SC}_{\mathrm{up}}\right.$ and $\left.\mathrm{N}_{\mathrm{st}-\mathrm{up}}\right)$ and lower $\left(\mathrm{SC}_{\mathrm{lo}}\right.$ and $\left.\mathrm{N}_{\mathrm{st}-\mathrm{lo}}\right)$ leaf sides and as an average of both sides ( $\mathrm{SC}$ and $\mathrm{N}_{\mathrm{st}}$ ). Prior to the analyses of variance, the random effects of sampled row and replicates were investigated and the null hypotheses were accepted. In all cases, the means were compared using a Duncan post-hoc test for multiple comparison $(p<0.05)$.

If significant differences were observed among FS and DC, the uniformity of spray coverage among samples on each vine canopy was evaluated for each configuration by means of the uniformity index $\left(\mathrm{I}_{\mathrm{U}}\right)$ using Eq. 1 . The index was originally proposed by Chen et al. (2013) and recently used by Salcedo et al. (2020) considering only the upper leaf side, but was adjusted here to take into account the uniformity of spray coverage measured on both leaf sides. To further investigate the effect of FS and DC on the uniformity of spray coverage under real-field conditions, a two-way ANOVA was performed using $I_{U}$ as dependent variable.

$$
I_{U}=\frac{\sum_{i}^{C_{n \_ \text {up }}^{2}} u_{i}+\sum_{i}^{C_{n_{-l o w}}^{2}} u_{i}}{c_{n_{-} u p}^{2}+c_{n_{-} \text {low }}^{2}}
$$

where:

$I_{U}$ : uniformity index for spray coverage ( 0 to 1 , with higher values indicating greater uniformity); $i$ : order of comparison $\left(1,2, \ldots, C_{n_{-} u p}^{2}\right.$ or $\left.1,2, \ldots, C_{n_{-} l o w}^{2}\right) ;{ }_{n_{-} u p}$ or ${ }_{n \_l o w}$ : number of groups in a direction to be compared ( $\mathrm{n}$ is 3 for the $\mathrm{y}$-direction, i.e. canopy depth, or $\mathrm{z}$-direction, i.e. canopy height) for the upper $\left({ }_{n \_u p}\right)$ or lower $\left(n_{-}\right.$low $)$leaf sides; $C_{n \_u p}^{2}$ or $C_{n \_l o w}^{2}$ : total number of possible combinations of two comparisons (e.g. $C_{3_{\_} u p}^{2}=3$ for either the $\mathrm{y}$ or $\mathrm{z}$ direction and $C_{3 \_ \text {low }}^{2}=3$ for either the y or $\mathrm{z}$ direction); $u_{i}$ : outcome of Duncan post-hoc test for comparison of the two groups in one combination $\left(u_{i}=0\right.$ when they are significantly different, and $u_{i}=1$ when they are not significantly different).

In addition, the spray deposition qualities generated by the tested configurations were evaluated to define the most suitable spray application volume according to the treatment specification (e.g. insecticide or fungicide) in order to maximize the efficacy of spray application, while at the same time minimizing overspray. The thresholds provided by Syngenta Crop Protection AG and widely used by other authors were adopted (Chen et al., 2013; MirandaFuentes et al., 2015; Salcedo et al., 2020). Overspray was defined as any situation with spray coverage greater than $30 \%$, while effective insecticide and fungicide spray applications were considered at deposit densities higher than 30 and 70 stains $\mathrm{cm}^{-2}$, respectively, which are rather conservative thresholds. To verify the suitability of the thresholds used, the linear relationship and the correlation between $\mathrm{SC}$ and $\mathrm{N}_{\mathrm{st}}$, measured on both upper and lower leaf side, were evaluated for each configuration. Finally, dual y-axis charts with percentage of WSP not oversprayed and percentage of WSP with deposit density higher than the defined thresholds 
(y-axes) were used to define the optimal spray application volume (x-axis) for both insecticide and fungicides spray application.

\section{Results and discussion}

\section{Droplet size and velocity characteristics}

An overview of the most important droplet size and velocity characteristics of the XR 8002 nozzle spraying at $0.4 \mathrm{MPa}$ pressure without solenoid valve and with solenoid valve working at different duty cycles $(30 \%, 50 \%, 70 \%, 100 \%)$, and measured at $0.5 \mathrm{~m}$ under the spray boom is given in Table 2, with:

- $\mathrm{D}_{\mathrm{v} 0.1}, \mathrm{D}_{\mathrm{v} 0.25}, \mathrm{D}_{\mathrm{v} 0.5}, \mathrm{D}_{\mathrm{v} 0.75}, \mathrm{D}_{\mathrm{v} 0.9}$ being the volume diameter $(\mu \mathrm{m})$ below which smaller droplets constitute respectively $10,25,50,75$, and $90 \%$ of the total volume;

- $\mathrm{v}_{\mathrm{v} 0.1}, \mathrm{v}_{\mathrm{v} 0.25}, \mathrm{v}_{\mathrm{v} 0.5}, \mathrm{v}_{\mathrm{v} 0.75}, \mathrm{v}_{\mathrm{v} 0.9}$ being the droplet velocity $\left(\mathrm{m} \mathrm{s}^{-1}\right)$ below which slower droplets constitute respectively $10,25,50,75$, and $90 \%$ of the total spray volume;

- $\mathrm{V}_{100}$ being the percentage of total spray volume with droplets $\leq 100 \mu \mathrm{m}(\%)$, also referred to as the driftables fines.

The PDPA measurements indicate that the addition of a solenoid valve to the spray system and operated at $100 \%$ duty cycle slightly reduced the droplet size of the tested standard flat fan nozzle $\left(D_{v 0.5}\right.$ no solenoid valve vs. solenoid valve at $100 \% \mathrm{DC}=250$ vs. $\left.228 \mu \mathrm{m}\right)$. Duty cycle had no clear effect on droplet size, although a very small physical effect towards smaller droplets with reduced duty cycle was observed for the finest droplets $\left(D_{v 0.1}, D_{v 0.25}\right.$, $\mathrm{D}_{\mathrm{v} 0.5}$ ), i.e. maximum $10 \mu \mathrm{m}$ reduction from 100 to $30 \%$ duty cycle. The percentage of driftables fines $\left(\mathrm{V}_{100}\right)$ increased due to the presence of a solenoid valve and as duty cycle decreased. Butts et al. (2019) reported variable effects of the addition of the solenoid valve on the droplet size distribution from venturi nozzles but, similar to this study, they found a decrease in droplet size for most non-venturi nozzles. Those authors also measured the nozzle tip pressure and found a decrease in pressure across the solenoid valve with nonventurri nozzles, which does not explain the decrease in droplet size from those nozzles. A lower $\mathrm{D}_{\mathrm{v} 0.5}$ in the presence of a solenoid valve could indicate a finer droplet size spectrum confirming the higher $V_{100}$ value. Further research should be conducted to identify the underlying cause. Unlike this study, Butts et al. (2019) found that droplet size generally increased and percentage of driftable fines reduced as duty cycle decreased, for both venturi and non-venturi nozzles. Similarly, Giles and Comino (1990) reported a significant effect of duty cycle on $\mathrm{D}_{\mathrm{v} 0.1}$ and $\mathrm{D}_{\mathrm{v} 0.5}$ for a flat fan nozzle, with an increase in droplet size as duty cycle decreased. According to those authors, the effects on droplet size spectra were most often observed as the generation of a few large droplets rather than a shift of the entire spectrum to larger diameters. In accordance with Butts et al. (2019), it is therefore suggested that the increase in spray drift potential with the PWM system due to the reduced droplet size is minimal, especially when compared to conventional sprayers implementing similar flow rate changes. Wei et al. (2020) also reported increased droplet sizes with decreased duty cycles for XR 8001 to XR 8006 flat fan nozzles at $0.276 \mathrm{MPa}$ using two different PWM systems from different manufacturers. These findings were explained by an increase in the travel distance of the spray sheet (i.e. the distance between the nozzle orifice 


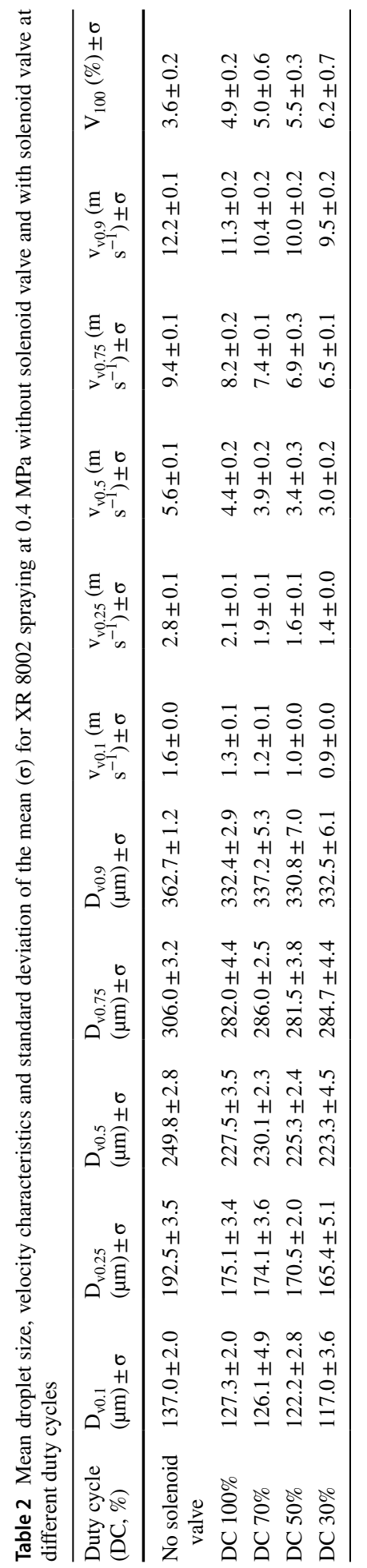


and the breakup of the sheet) with decreased duty cycle, making them more prone to larger droplets. Furthermore, when duty cycle decreased, the authors noticed an increase in pressure upstream of the valve, whereas the activation pressure (i.e. the pressure between the valve and the nozzle orifice when the valve is open) decreased. The operating pressure was not adjusted when the duty cycle changed, contrary to this study. The droplet size distribution of the XR 8002 nozzle controlled by the TeeJet PWM system showed little variation with duty cycle in both the study of Wei et al. (2020) and in this study. Between 100 and $30 \%$ duty cycle, Wei et al. (2020) found coefficients of variation of $1.7 \%, 2.1 \%$ and $4.0 \%$, and maximum differences of $4 \mu \mathrm{m}, 7 \mu \mathrm{m}$ and $27 \mu \mathrm{m}$ for $\mathrm{D}_{\mathrm{v} 0.1}, \mathrm{D}_{\mathrm{v} 0.5}$, and $\mathrm{D}_{\mathrm{v} 0.9}$, respectively. In this study, differences between 100 and $30 \%$ were up to $10 \mu \mathrm{m}$ and coefficients of variation ranged from $3.8 \%$ for $\mathrm{D}_{\mathrm{v} 0.1}$ to $0.8 \%$ for $\mathrm{D}_{\mathrm{v} 0.9}$. At smaller droplet sizes, a larger variation was thus found in this study than in the study by Wei et al. (2020), whereas at larger droplet sizes, lower variation was found. These findings are hard to explain as different measuring methodologies were used. More specifically, Wei et al. (2020) measured 10000 effective droplets over a $35 \mathrm{~cm}$ range of the long-axis spray pattern while not adjusting the operating pressure with changing duty cycle whereas, in this study, the entire spray pattern was scanned, a minimum of 10000 droplets measured and operating pressure was kept constant at $0.4 \mathrm{MPa}$ over the different duty cycles.

The addition of a solenoid valve also considerably reduced the droplet velocity of the tested standard flat fan nozzle ( $\mathrm{v}_{\mathrm{v} 0.5}$ no solenoid valve vs. solenoid valve at $100 \% \mathrm{DC}=5.6$ vs. $4.4 \mathrm{~m} \mathrm{~s}^{-1}$ ). Droplet velocity was decreased by decreasing the duty cyle in this study. Giles and Ben-Salem (1992) also found decreased droplet velocities with decreased duty cycle with a flat fan nozzle (tested at $60 \%, 30 \%$ and $10 \%$ duty cycle), although the effects were relatively small and not always significant. Likewise, Butts et al. (2018) reported decreased droplet velocities with decreased duty cycle for venturi and non-venturi nozzles, but found that the average droplet velocity either remained the same or slightly increased when a solenoid valve was operated at $100 \%$ duty cycle when compared to the standard configuration without a solenoid valve. The reduction in droplet velocity can be explained by the decrease in nozzle tip or activation pressure with the addition of a solenoid valve or with decreased duty cycle, as observed by Butts et al. (2019) and Wei et al. (2020) and as reported earlier. As suggested by Butts et al. (2018), the droplet velocity reduction using the PWM system could increase spray drift potential and reduce canopy penetration. However, Giles et al. (2002) demonstrated that the reduction in droplet velocity with flow rate was considerably lower with pulsed flow control than with conventional pressure control. This implies that the potential increase in drift potential with a PWM sprayer at lower duty cycles is lower than that obtained with a conventional sprayer with pressure-based control for a similar flow rate decrease.

\section{Spray coverage under field-standardized conditions (plot L)}

The mean spray coverage measurements (SC, \%) at the three canopy heights on the edges of the vine canopies are shown in Fig. 4. Irrespective of FS and DC, mean SC was always lowest at $2.0 \mathrm{~m}$ canopy height $(\mathrm{H} 3)$ with a maximum of $27.2 \%$ at the highest spray volume applied (585.0 $1 \mathrm{ha}^{-1}$, FS4_DC100) and a minimum of 6.6\% at the lowest spray volume (87.8 $1 \mathrm{ha}^{-1}$, FS8_DC30) (Table 7 in appendix). On the other hand, very high mean SC values were found at the other canopy heights, ranging from 28.4 to $87.2 \%$ at $0.8 \mathrm{~m}$ and from 38.6 to $86.8 \%$ at $1.4 \mathrm{~m}$ height for the extremes in spray volume, with a proportional increase in relation to the applied volume. The discrepancy between the lower canopy 


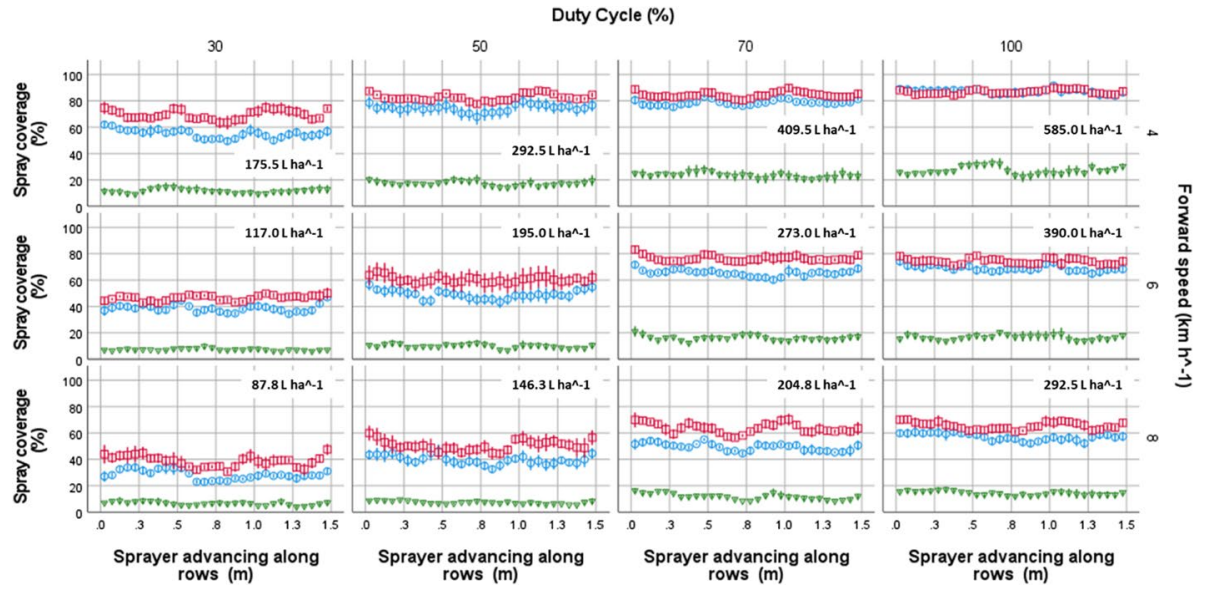

Fig. 4 Spray coverage (\%) on the WSP sections obtained from the WSP lines placed horizontally at different heights above the ground $(\mathrm{H} 1=0.8 \mathrm{~m}$, light-blue circles; $\mathrm{H} 2=1.4 \mathrm{~m}$, red squares; $\mathrm{H} 3=2.0 \mathrm{~m}$, green triangles-down) for the different forward speed and duty cycle combinations. The symbols show the mean \pm standard error of the mean. The applied volumes $\left(\mathrm{lha}^{-1}\right)$ are also shown for the different combinations of duty cycle and forward speed (Color figure online)

heights ( $\mathrm{H} 1$ and $\mathrm{H} 2$ ) and the highest one (H3) could be explained by the sprayer configuration. On each sprayer side, only the six lower nozzles were activated (Fig. 1). According to preliminary tests, this should have been the best configuration to maximize the canopy deposition and minimize the spray losses to the air. Compared to the lower heights, less spray was thus directed to the top of the vegetation, resulting in lower spray coverage at $2.0 \mathrm{~m}$ canopy height. For all canopy heights, mean SC increased with increasing DC. Furthermore, the differences in mean SC between 0.8 and $1.4 \mathrm{~m}$ became less pronounced as DC increases, suggesting the influence of DC on the vertical spray profile. Furthermore, Fig. 4 shows more pronounced variations in SC profile at lower DC, regardless of FS, suggesting an effect of DC on SC variability along the travel direction. Indeed, this effect was confirmed by the three-way ANOVA which showed a significant effect of DC, FS and LP on

Table 3 Results of the three-way ANOVA $(p<0.05)$ for the spray coverage coefficient of variation $(\mathrm{CV}, \%)$, analysed separately for the horizontal $\left(\mathrm{CV}_{\text {sprayer track }}, \%\right)$ and vertical $\left(\mathrm{CV}_{\text {canopy height, }} \%\right)$ WSP lines

\begin{tabular}{|c|c|c|c|c|c|c|}
\hline Sources & \multicolumn{3}{|c|}{$\mathrm{CV}_{\text {sprayer track }}(\%)$} & \multicolumn{3}{|c|}{$\mathrm{CV}_{\text {canopy height }}(\%)$} \\
\hline \multicolumn{7}{|l|}{ Main effects } \\
\hline Forward speed (FS) & 2 & $2.58 \mathrm{E}-40$ & $* * *$ & 2 & $5.97 \mathrm{E}-17$ & $* * *$ \\
\hline Duty cycle (DC) & 3 & $3.62 \mathrm{E}-29$ & $* * *$ & 3 & $5.63 \mathrm{E}-21$ & $* * *$ \\
\hline WSP line position (LP) & 2 & $9.75 \mathrm{E}-75$ & $* * *$ & 2 & 0.010 & $* *$ \\
\hline \multicolumn{7}{|l|}{ Interactions } \\
\hline $\mathrm{FS} \times \mathrm{DC}$ & 6 & 0.168 & NS & 6 & 0.001 & $* * *$ \\
\hline $\mathrm{FS} \times \mathrm{LP}$ & 4 & 0.001 & $* * *$ & 4 & 0.911 & NS \\
\hline $\mathrm{DC} \times \mathrm{LP}$ & 6 & $8.31 \mathrm{E}-09$ & $* * *$ & 6 & 0.942 & NS \\
\hline $\mathrm{FS} \times \mathrm{DC} \times \mathrm{LP}$ & 12 & 0.467 & NS & 12 & 0.968 & NS \\
\hline
\end{tabular}

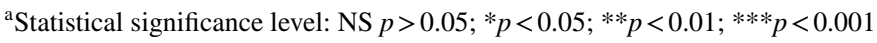


$\mathrm{CV}_{\text {sprayer track }}$ (Table 3). Despite different spray volumes due to differences in FS, DC thus influences the uniformity of spray coverage along the sprayer travel direction, with higher variability at lower DC. The not significant interaction FSxDC indicates that the influence of DC on SC variability is independent of FS. Concurrently, the spray coverage variation increased with increasing FS irrespective of DC level. This trend can be explained by a decrease in application volume, as well as a decrease in air volume delivered per linearmeter of row when the FS was increased. Świechowski et al. (2004) demonstrated that the penetration of air in the canopy was fully affected by the sprayer travel speed especially for a cross-flow sprayer characterized by high volume/low speed air jet, affecting the SC uniformity in vineyard (Cerruto, 2007). Based on a visual assessment of Fig. 4, the variation in spray coverage was lowest at $2.0 \mathrm{~m}$ canopy height. The significant interactions FSxLP and DCxLP furthermore suggest effects of both FS and DC on the vertical spray profile, not only along the sprayer travel direction.

To illustrate the effects on the vertical spray profiles, the mean spray coverage values (SC \%) at three distances along the canopy height are shown in Fig. 5. The visual analysis shows that, independent from FS and DC, the SC profiles at the three distances align almost perfectly. Indeed, very little SC variation was noticed between the different vertical WSP lines. Over the 3 distances, SC ranged from 74.3 to $76.7 \%$ at the maximum spray volume and from 21.8 to $24.0 \%$ at the minimum spray volume (Table 7 in appendix). As already mentioned, the use of only the lower six nozzles per sprayer side explains the lower SC in the top part of the WSP lines. The highest SC was measured at the central part of the WSP lines. However, irrespective of FS, increasing DC increased SC at the bottom part of the vegetation, resulting in values equal or similar to those observed at the central part. SC was also found to increase with DC at the central and top of the vegetation, but to a lesser extent than at the bottom. The three-way ANOVA shows a significant effect of DC, as well as FS, LP, and the interaction FSxDC on $\mathrm{CV}_{\text {canopy height }}$ (Table 3). The significant interaction FSxDC underlines the combined effect of FS and DC on the vertical spray profile irrespective of the sprayer travel position. Interestingly, the significant effect of LP confirms the results achieved using horizontal WSP lines: the DC and FS affect the SC variability along the travel direction.

The effect of DC on both $\mathrm{CV}_{\text {sprayer track }}$ and $\mathrm{CV}_{\text {canopy height }}$ was investigated in more detail for each FS separately using a Duncan post-hoc test for multiple comparisons. The results are shown in Fig. $6 \mathrm{a}$ and $\mathrm{b}$ for $\mathrm{CV}_{\text {sprayer track }}$ and $\mathrm{CV}_{\text {canopy height, }}$, respectively. A clear trend within FS was observed, with a decrease in $\mathrm{CV}$, and thus a decrease in SC variability, as DC increases from 30 to $100 \%$, although not always significant. Regardless of FS, the $\mathrm{CV}_{\text {sprayer track }}$ measured for the extremes 30 and $100 \%$ DC were in all cases significantly different while intermediate values measured for 50 and $70 \%$ DC were not significantly different. Concurrently, two groups could be distinguished for $\mathrm{CV}_{\text {canopy height }}$ with 30 and $50 \%$ DC being significantly different from 70 and $100 \%$ DC, except at the lowest forward speed of $4 \mathrm{~km} \mathrm{~h}^{-1}$ where $\mathrm{CV}_{\text {canopy height }}$ at 70 and $100 \%$ DC also significantly differed. In general, $\mathrm{CV}_{\text {canopy height }}$ was higher than $\mathrm{CV}_{\text {sprayer track }}$ due to the lower coverage in the top part of the canopy. Finally, the comparison of $\mathrm{CV}_{\text {sprayer track }}$ obtained from configurations FS4_DC50 and FS8_DC100, where the same volume was applied $\left(292.51 \mathrm{ha}^{-1}\right)$ by different combinations of DC and FS, were significantly different, confirming the effect of DC and FS on the variability of spray coverage.

The use of the field-standardized methodology, with WSP lines fixed on a rigid wooden frame and completely exposed to the spray jets without interference of vine leaves, allowed a broad comparison of the effect of DC on the SC variability, both along the sprayer travel direction and within the spray profile. However, this practice deviates from reality 
Duty Cycle (\%)

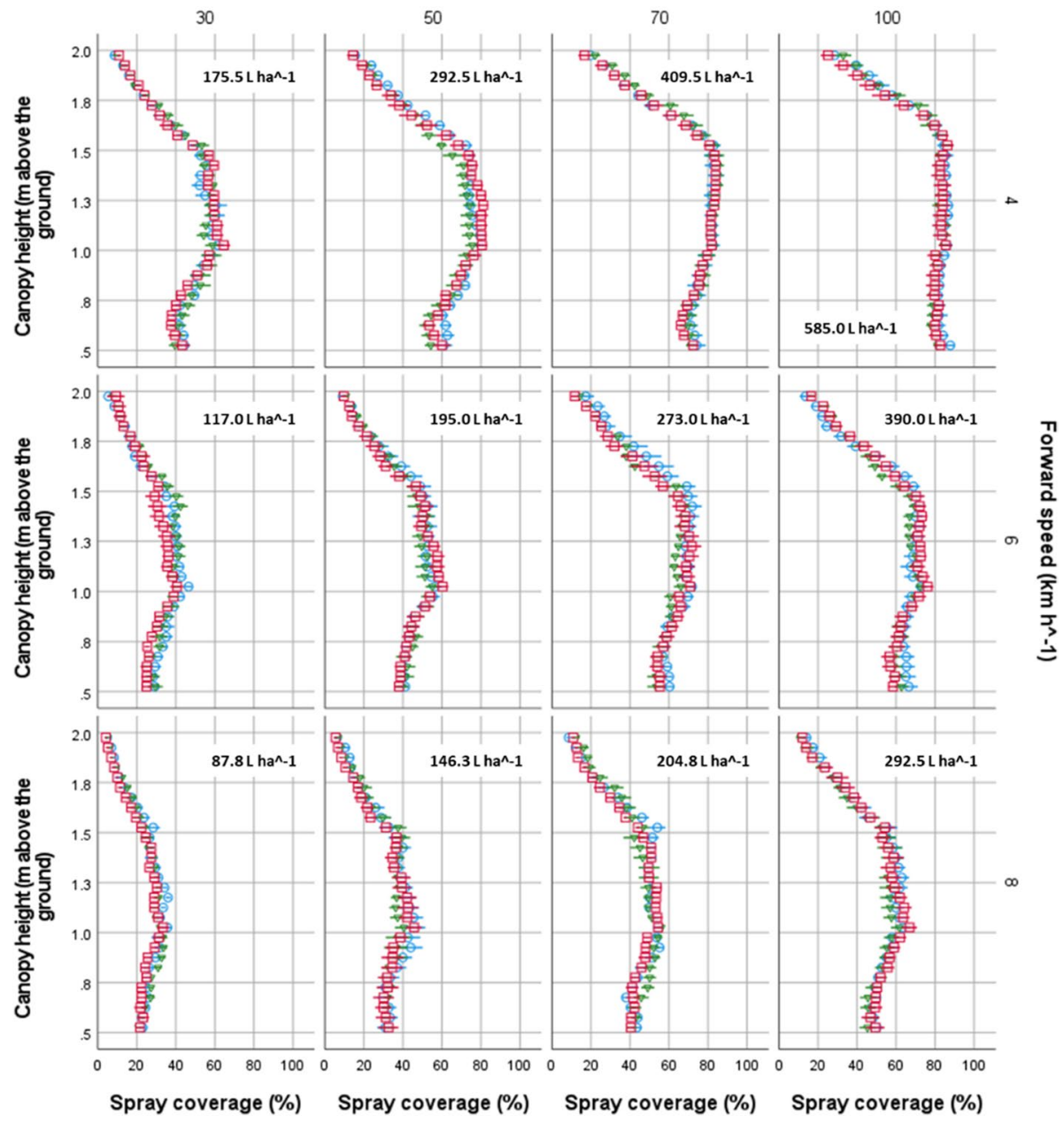

Fig. 5 Spray coverage (\%) on the WSP sections obtained from the WSP lines placed vertically at different advancing positions $(\mathrm{D} 1=0 \mathrm{~m}$, light-blue circles; $\mathrm{D} 2=1 \mathrm{~m}$, red squares; D3 $=2 \mathrm{~m}$, green triangles-down) for the different forward speed and duty cycle combinations. The symbols show the mean \pm standard error of the mean. The applied volumes $\left(1 \mathrm{ha}^{-1}\right)$ are also shown for the different combinations of duty cycle and forward speed (Color figure online)

as, during real spray applications, the leaves move due to the sprayer fan airflow and they interfere with each other and with the spray cloud depending on their position within the vine canopy and on the canopy density. Although no similar experimental field research on $3 \mathrm{D}$ crops is available in the literature, the effect of $\mathrm{DC}$ on $\mathrm{CV}_{\text {sprayer track }}$ (Fig. 6a) was comparable with the results found by Pierce and Ayers (2001). Those authors used boom sprayers and a similar method of measurement (CV \% of SC measured along long WSP strips). Pierce and Ayers (2001), using PWM valves pulsing at $15 \mathrm{~Hz}$ frequency, found $\mathrm{CV} \%$ higher (in the range from 65 to $10 \%$ for 25 to $100 \%$ DC) compared to those found in this study (in the range of 25 to $15 \%$ for 30 to $100 \% \mathrm{DC}$ at $8 \mathrm{~km} \mathrm{~h}^{-1}$ ). Recently, Mangus et al. (2017) found similar results using a dynamic, theoretical, on-ground spray coverage 

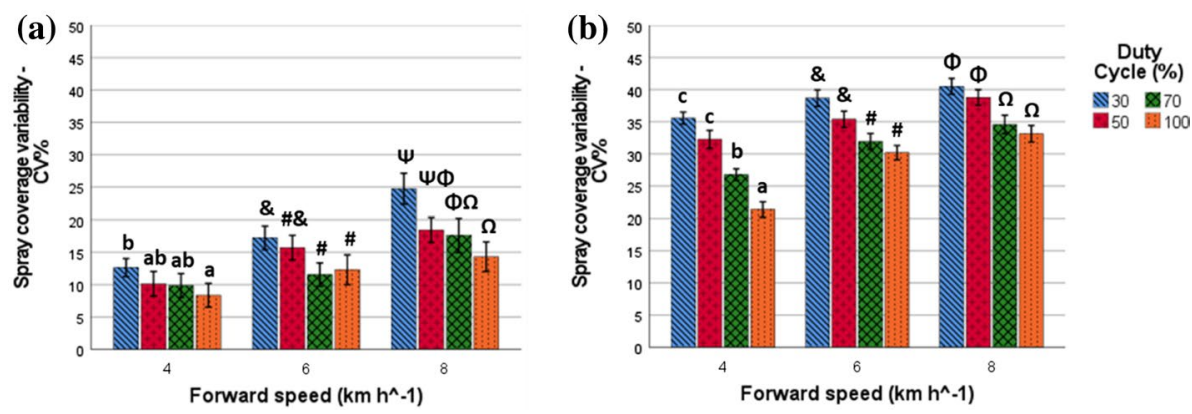

Fig. 6 Comparison of $\mathbf{a} \mathrm{CV}_{\text {sprayer track }}$ and $\mathbf{b} \mathrm{CV}_{\text {canopy height }}$ for the different forward speed and duty cycle combinations. The bars show the mean \pm standard error of the mean. Different letters and symbols on the bars denote significant differences (Duncan post hoc test, $p<0.05$ )

simulation for a boom sprayer equipped with a PWM system pulsing at $10 \mathrm{~Hz}$. They reported that the coverage might result in scarce homogeneity due to areas with under- or over-spray. A similar trend with an increase in SC homogeneity due to increasing DC was also found by Jiang et al. (2016) with a single nozzle under dynamic laboratory conditions. The effect of FS on the SC homogeneity, evaluated along the sprayer travel direction, confirmed the results found by Deng et al. (2013) in laboratory experiments. Those authors suggest that, as higher travel speeds can enhance the spray heterogeneity along the travel direction (especially when low DC are used), the appropriate traveling speed during pesticide application with PWM system should be carefully chosen so that a more uniform spray distribution is achieved. While in the literature similar results were found as those presented here, it must be emphasized that they refer to experiments carried out with boom sprayers under controlled laboratory conditions and lower frequencies. Nevertheless, a few published data are available about the effect of PWM system (with special focus on DC) on the spray pattern along the boom. Although Pierce and Ayers (2001) suggest that pulsing nozzles had no effect on the spray pattern along the boom, Deng et al. (2020), working with flat fan nozzles ( $110^{\circ}$ spray angle), demonstrated the effect of DC. According to those authors, DC affects (i) the distribution of the spray pattern as it narrows with decreasing flowrates and (ii) the spray angle as it reduces with decreasing flowrate. When the flowrate decreased from 100 to $40 \%$ (corresponding to the DC reduction), the average spray angle decreased by $49.8^{\circ}$. The increase in $\mathrm{CV}_{\text {canopy height }}$ with the decrease of DC from 100 to $30 \%$ (Fig. 6b) found in this study was probably attributable to the combined effect of both these phenomena described by Deng et al. (2020). However, it should be noted that the spray angle can decrease or increase with duty cycle depending on the model and size of the nozzle, the flow rate, and the nozzle tip pressure. It is necessary to take into account that both the forces exerted by the liquid (flow rate, pressure) and the tangential forces produced by the valve are acting on the spray angle.

\section{Spray coverage and deposit density under real field conditions (plot S)}

The spray coverage results obtained under real field conditions (plot $\mathrm{S}$ ) on the upper $\left(\mathrm{SC}_{\mathrm{up}}\right)$ and lower leaf side $\left(\mathrm{SC}_{\mathrm{lo}}\right)$ are shown in Fig. 7 through a colour map for the different $\mathrm{FS}$ and DC combinations. Heterogeneous $\mathrm{SC}_{\mathrm{up}}$ and $\mathrm{SC}_{\mathrm{lo}}$ were visually detected. As expected, within each FS, higher SC was obtained at $100 \%$ DC, when higher spray volumes were 

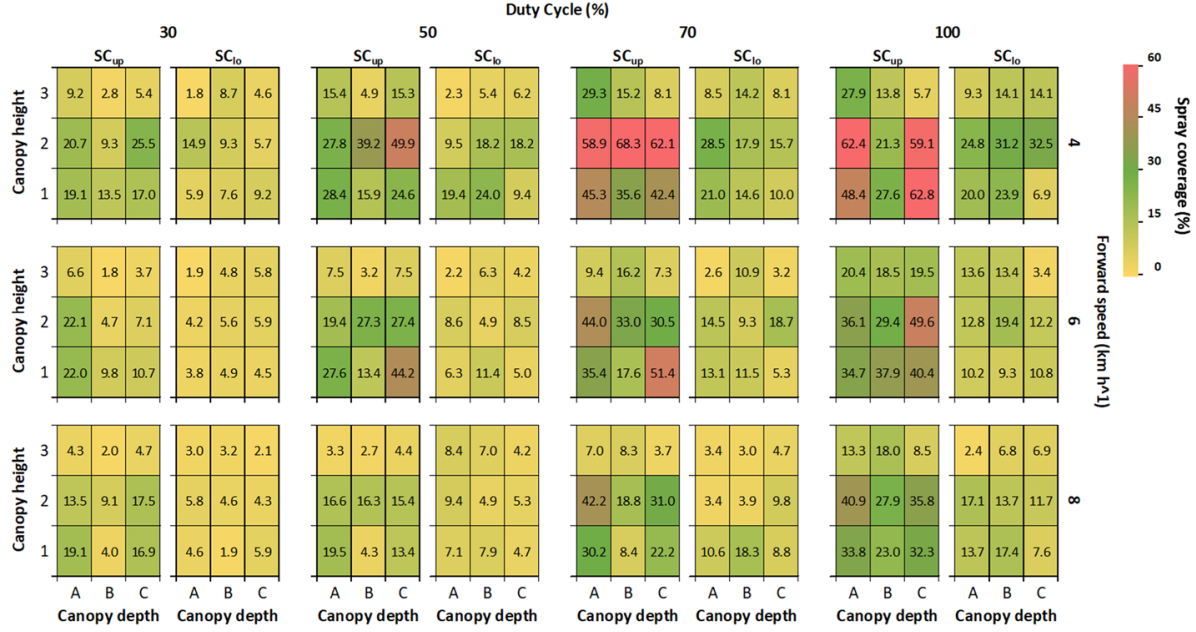

Fig. 7 Mean spray coverage (\%) on the WSP placed on the upper $\left(\mathrm{SC}_{\mathrm{up}}\right)$ and lower $\left(\mathrm{SC}_{\mathrm{lo}}\right)$ leaf sides at different depths $(\mathrm{A}=$ right edge; $\mathrm{B}=$ middle; $\mathrm{C}=$ left edge $)$ and heights $(1=$ bottom; $2=$ middle; $3=$ top $)$ in the canopy for the different forward speeds and duty cycle combinations

applied, whereas lower values were measured at $30 \% \mathrm{DC}$. In addition, $\mathrm{SC}_{\mathrm{lo}}$ was always lower than $\mathrm{SC}_{\text {up }}$ with an average upper/lower ratio equal to 6.5, 8.1 and 6.7 for 4,6 and $8 \mathrm{~km} \mathrm{~h}^{-1}$, respectively; the values were comparable to those found by Hołownicki et al. (2002) in apple tree canopy working at 4 and $6 \mathrm{~km} \mathrm{~h}^{-1}$. Detailed results averaged over the upper and lower leaf sides (SC) are shown in Table 8 in appendix. The four-way ANOVA (Table 4) shows that FS, DC and sample positions within the canopy, i.e. canopy depth (Dlev) and canopy height (Hlev), significantly affected spray coverage, but some differences occured depending on leaf side. The effect of FS and DC, as well as Dlev and Hlev on the spray coverage can be attributable to the different applied spray volumes. No significant interaction effects were found for SC. The separate analysis of spray coverage according to leaf side showed a significant interaction effect of DlevxHlev, underlining that the effect of canopy depth on spray coverage changes depending on the canopy height level. This confirms the heterogeneity of spray coverage within the vine canopies.

The two-way ANOVA showed no significant effect of FS $[\mathrm{F}(2,12)=0.056, p=0.946]$, $\mathrm{DC}[\mathrm{F}(3,12)=0.296, p=0.827)$ or $\mathrm{FSxDC}[\mathrm{F}(6,12)=2.574, p=0.077]$ on the uniformity index $\left(\mathrm{I}_{\mathrm{U}}\right)$ under real field conditions. Surprisingly, very similar $\mathrm{I}_{\mathrm{U}}$ values (around 0.8 ) were reported for both FS and DC (Fig. 8). The $\mathrm{I}_{U}$ values obtained were in the same range as those found by other authors in a young apple orchard (Chen et al., 2013; Salcedo et al., 2020), even though they only took into account the upper leaf side. The results found under real field conditions deviated from those obtained under field-standardized conditions in which the effect of FS and DC on the uniformity of spray coverage was well defined (Fig. 8 vs. Fig.6). This effect is not so surprising considering that, under real field conditions, the short WSP were directly stapled to the leaves to simulate the real leaf behaviour influenced by the airstream and spray cloud generated by the sprayer, whereas, under fieldstandardized conditions, the long WSP were fixed to wooden supports and were completely exposed. Even if the positive effect of DC on spray coverage (due to the increase in spray volume) is well defined, the effect of $\mathrm{DC}$ on the uniformity of spray coverage $\left(\mathrm{I}_{\mathrm{U}}\right)$ was nullified under real field conditions. The turbulent airflow generated by the airblast sprayer, 


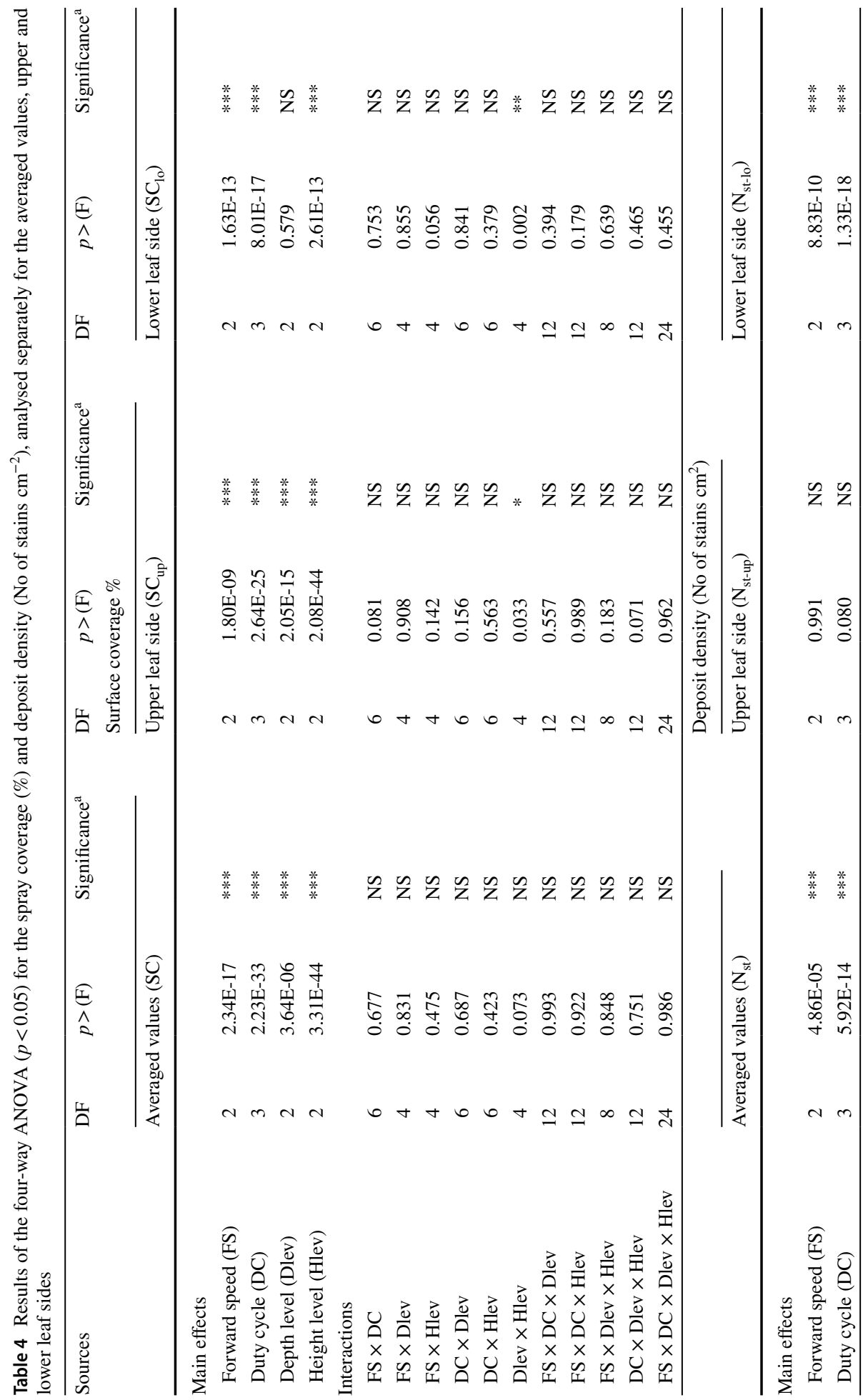




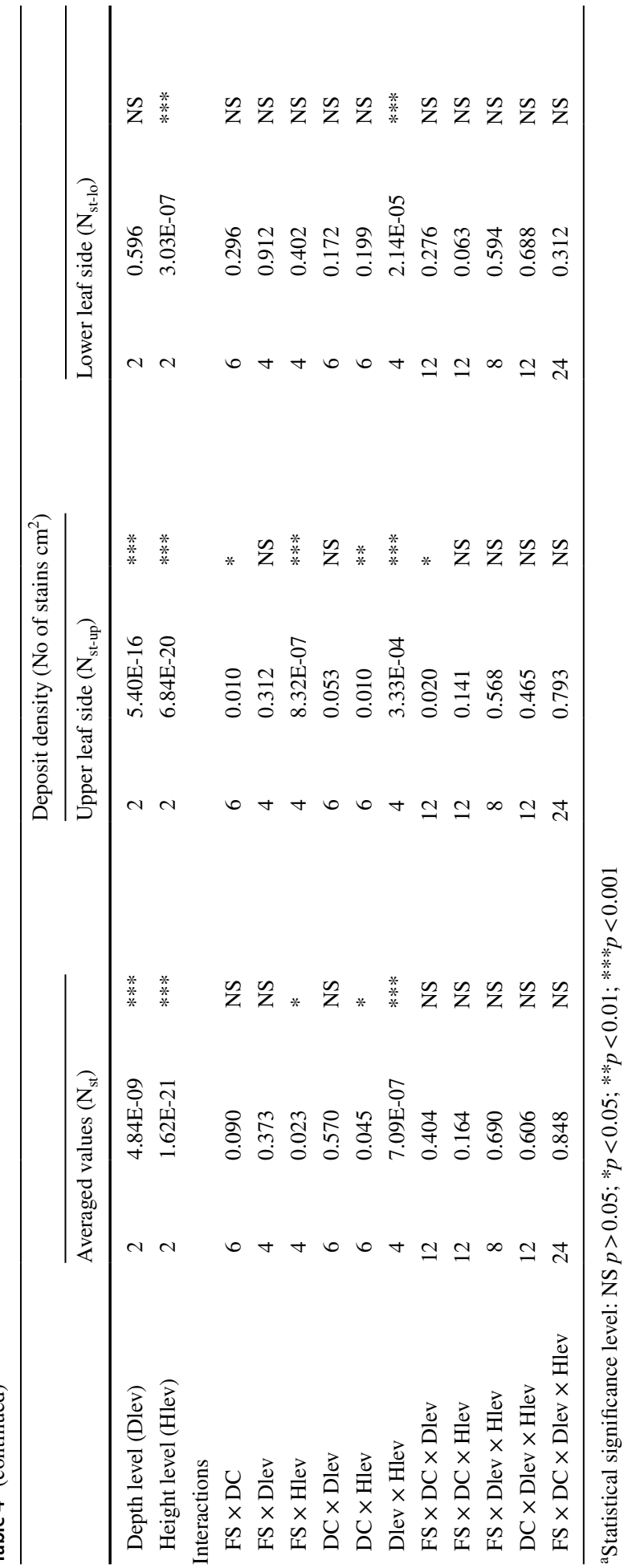


(a)

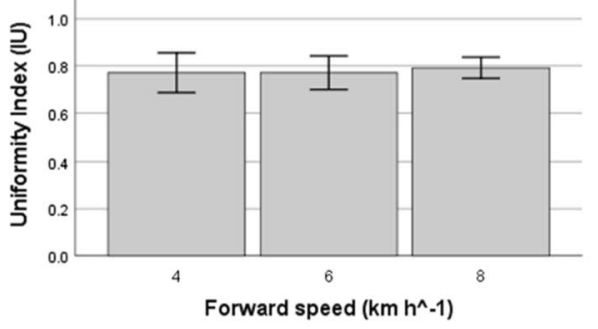

(b)

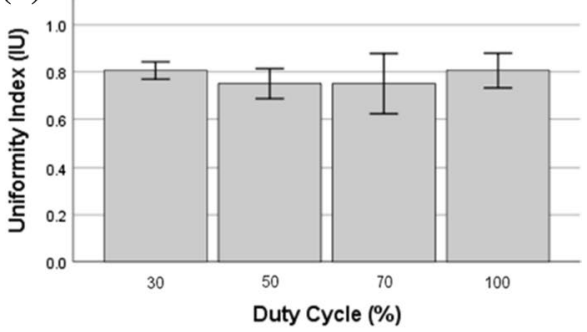

Fig. 8 Uniformity index $\left(I_{U}\right)$ averaged over a forward speed and $\mathbf{b}$ duty cycle. The bars show the mean \pm standard error of the mean

used to guide the spray jet into the canopy, eliminated the on-off effect of the PWM solenoids on the spray coverage uniformity inside the canopy, irrespective of DC used. According to Duga et al. (2015) the outlet airflow pattern from sprayers is strongly related to the spray deposition along the canopy height, thus underlining the importance of appropriate and dedicated adjustment of the airflow velocity and direction to the canopy architecture in order to maximize and to obtain uniform deposition throughout the canopy and concurrently reduce spray losses. Fox et al. (2003), investigating the variability of spray coverage, demonstrated through experimental field trials on nursery trees that, for a given spray volume, a factor four to five difference in spray coverage can be found between replicates with WSP collectors placed in the same location (stapled to the same leaf). This variation can be attributed to the interaction between leaves and sprayer airflow, as found by Li et al. (2021). Those authors studied the leaf movement under different airflow velocities and the influence of the leaf aerodynamic response on droplet coverage ratio.

Figure 9 displays a colour map of deposit density on the upper $\left(\mathrm{N}_{\mathrm{st}-\mathrm{up}}\right)$ and lower leaf side $\left(\mathrm{N}_{\mathrm{st}-\mathrm{lo}}\right)$ measured at three heights and three depths in the vine canopies for the different FS and DC combinations. In general, within FS, the deposit density increased with
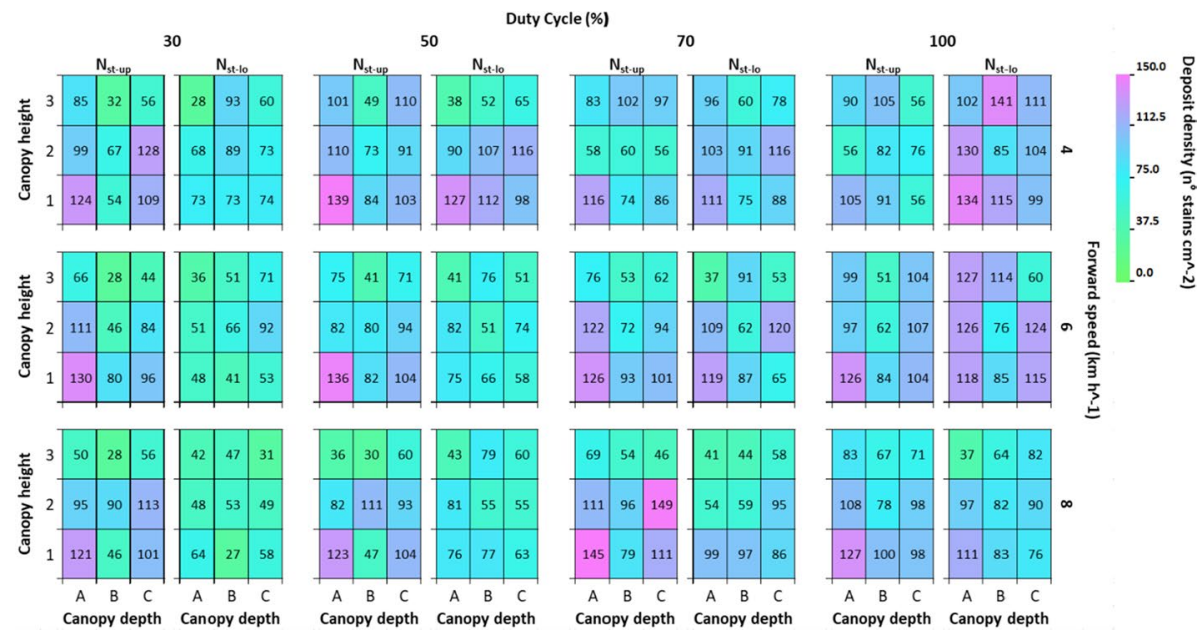

Fig. 9 Mean deposit density (no stains $\mathrm{cm}^{-2}$ ) on the WSP placed on the upper $\left(\mathrm{N}_{\text {st-up }}\right)$ and lower $\left(\mathrm{N}_{\text {st-lo }}\right)$ leaf sides at different depths $(\mathrm{A}=$ right edge; $\mathrm{B}=$ middle; $\mathrm{C}=$ left edge $)$ and heights $(1=$ bottom; $2=$ middle; $3=$ top) in the canopy for the different forward speed and duty cycle combinations 
DC, both at the upper and lower leaf side. Furthermore, deposit density was always higher at the upper leaf side, except for FS4_DC100 and FS6_DC100 due to massive overlap of stains on the upper leaf side, as also described by Fox et al. (2003) and Grella et al. (2020). Table 4 shows the results of the four-way ANOVA. Even if the main effect of FS and DC on $\mathrm{N}_{\text {st-up }}$ was not significant, the significant interaction FSxDC indicates that the effect of FS is dependent on the DC as the overlap of stains becomes more considerable as the applied spray volume increases, resulting in a flattening of deposit density, even if $\mathrm{SC}_{\mathrm{up}}$ was considerably higher at higher spray volumes (Fig. 7). In contrast, the main effects of FS and DC on $\mathrm{N}_{\text {st-lo }}$ were significant as the lower leaf side is generally less exposed to the spray jet, thus being less subjected to stain overlaps. Similarly, FS and DC had a significant effect on the deposit density averaged over both leaf sides $\left(\mathrm{N}_{\mathrm{st}}\right)$. In addition, Dlev and Hlev significantly affected $\mathrm{N}_{\mathrm{st}-\mathrm{up}}, \mathrm{N}_{\mathrm{st}-\mathrm{lo}}$ and $\mathrm{N}_{\mathrm{st}}$. Interestingly, the significant interaction FSxDCxDlev on $\mathrm{N}_{\text {st-up }}$ indicates the effect of both FS and DC on the canopy spray penetration: generally lower deposit density was noticed for the middle depth of the canopy irrespective of height position, even if some exceptions can be observed (Fig. 9). Detailed results averaged over the upper and lower leaf sides $\left(\mathrm{N}_{\mathrm{st}}\right)$ are shown in Table 9 in appendix.

\section{Spray deposition qualities for the definition of optimal spray application volume}

Figure 10 shows the relationships between $\mathrm{SC}$ and $\mathrm{N}_{\mathrm{st}}$ measured under real field conditions for the different FS and DC combinations. In line with Chen et al. (2013), WSP with SC higher than 30\% (dash-dotted black line, Fig. 10) were classified as over-sprayed, thus taking into account that high coverage doesn't necessarily imply an effective spray application (Garcerá

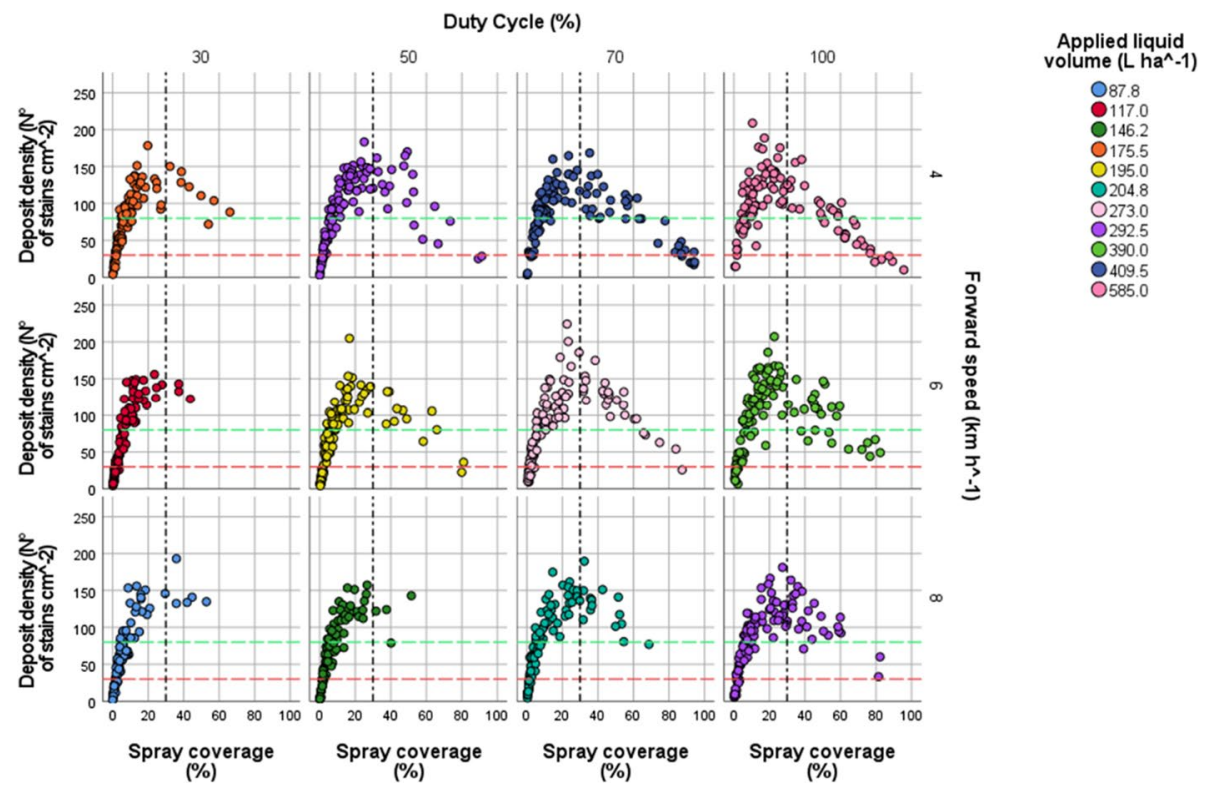

Fig. 10 Plots of deposit density (no of stains $\mathrm{cm}^{-2}$ ) and spray coverage (\%) for the different forward speed and duty cycle combinations. Different colours represent the different applied spray volume $\left(1 \mathrm{ha}^{-1}\right)$. Horizontal dashed red and green lines represent the deposit density thresholds for effective insecticide (30 stains $\mathrm{cm}^{-2}$ ) and fungicide applications $\left(70\right.$ stains $\left.\mathrm{cm}^{-2}\right)$, respectively. The vertical dash-dotted black line represents the spray coverage threshold for the overspray situation (30\%). The thresholds were recommended by Syngenta Crop Protection AG (Color figure online) 
et al., 2011). Thresholds of 30 and 70 stains $\mathrm{cm}^{-2}$ were used to evaluate $\mathrm{N}_{\mathrm{st}}$ for effective insecticide and fungicide application, respectively (Salcedo et al., 2020; Zhu et al., 2011). As demonstrated by field trials conducted within best management practices training programs in agriculture (TOPPS-Prowadis Project, 2014), an increase in the application rate might increase the spray coverage but not the biological efficacy of the PPP. The scatter plots in Fig. 10 confirm that the increase of applied spray volume results in an increment of SC with a marked overspray situation. It is therefore often possible to reduce spray volumes without harming the treatment effectiveness. Indeed, in accordance to the results found by other authors (Grella et al., 2020), the best linear relationships between SC and $\mathrm{N}_{\mathrm{st}}$ were generally obtained with WSP characterized by SC below $20 \%$. These relationships are presented in Table 5 . However, even if only those WSP collectors were considered, the correlation between SC and $\mathrm{N}_{\mathrm{st}}$ demonstrates that the Pearson's coefficient $(\rho)$ and determination coefficient $\left(r^{2}\right)$ decrease with applied spray volume. It can therefore be concluded that besides WSP with SC above 20\% (Fox et al., 2003; Salcedo et al., 2020), also those with SC below $20 \%$ but sprayed with excessive spray volume are characterized by stain overlap. Although the $20 \%$ SC threshold was defined as the most suitable for $\mathrm{N}_{\mathrm{st}}$ evaluation of WSP collectors in order to minimize the effect of overlapping stains, the $30 \%$ threshold (as indicated by the WSP manufacturer and other authors) was nevertheless considered acceptable for $\mathrm{N}_{\mathrm{st}}$ measurements.

Based on these criteria, the percentage of not over-sprayed WSP collectors and the percentage of WSP collectors characterized by $\mathrm{N}_{\mathrm{st}}$ higher than 30 and 70 stains $\mathrm{cm}^{-2}$ were selected and plotted against the applied spray volume to obtain the best spray application volumes to minimize over-spray and maximize the density of spray deposition on the vine leaves as indicated by the intersection of the curves. The results are shown in Fig. 11. Based on the vineyard field trials simulating spray applications under real field conditions, the most adequate spray volumes lie between 200 and $250 \mathrm{l} \mathrm{ha}^{-1}$ for insecticide treatments and between 300

Table 5 Linear relationships between the deposit density $\left(\mathrm{N}_{\mathrm{st}}\right.$, no stains $\left.\mathrm{cm}^{-2}\right)$ and surface coverage (SC, \%) for the WSP characterized by SC below $20 \%$

\begin{tabular}{llllll}
\hline ID univoque $^{\mathrm{a}}$ & Equations $^{2}$ & $\mathrm{r}^{2}$ & $p>(\mathrm{F})$ & Sign. $^{\mathrm{b}}$ & $\rho^{\mathrm{c}}$ \\
\hline FS4_DC30 & $\mathrm{y}=23.17+7.27 \mathrm{x}$ & 0.845 & $1.94 \mathrm{E}-39$ & $* * *$ & 0.919 \\
FS4_DC50 & $\mathrm{y}=26.60+6.59 \mathrm{x}$ & 0.838 & $3.24 \mathrm{E}-30$ & $* * *$ & 0.916 \\
FS4_DC70 & $\mathrm{y}=32.68+6.02 \mathrm{x}$ & 0.719 & $6.63 \mathrm{E}-18$ & $* * *$ & 0.848 \\
FS4_DC100 & $\mathrm{y}=44.86+5.88 \mathrm{x}$ & 0.496 & $1.94 \mathrm{E}-09$ & $* * *$ & 0.705 \\
FS6_DC30 & $\mathrm{y}=17.63+7.89 \mathrm{x}$ & 0.830 & $7.41 \mathrm{E}-40$ & $* * *$ & 0.911 \\
FS6_DC50 & $\mathrm{y}=21.23+7.24 \mathrm{x}$ & 0.803 & $4.51 \mathrm{E}-32$ & $* * *$ & 0.896 \\
FS6_DC70 & $\mathrm{y}=22.81+6.62 \mathrm{x}$ & 0.774 & $2.69 \mathrm{E}-24$ & $* * *$ & 0.880 \\
FS6_DC100 & $\mathrm{y}=27.08+6.98 \mathrm{x}$ & 0.735 & $1.07 \mathrm{E}-20$ & $* * *$ & 0.856 \\
FS8_DC30 & $\mathrm{y}=18.88+7.66 \mathrm{x}$ & 0.806 & $5.07 \mathrm{E}-37$ & $* * *$ & 0.898 \\
FS8_DC50 & $\mathrm{y}=21.12+7.07 \mathrm{x}$ & 0.825 & $1.00 \mathrm{E}-37$ & $* * *$ & 0.908 \\
FS8_DC70 & $\mathrm{y}=24.22+7.26 \mathrm{x}$ & 0.772 & $8.77 \mathrm{E}-26$ & $* * *$ & 0.879 \\
FS8_DC100 & $\mathrm{y}=22.03+6.99 \mathrm{x}$ & 0.787 & $3.49 \mathrm{E}-23$ & $* * *$ & 0.887 \\
\hline
\end{tabular}

The statistical significance and Pearson's correlation coefficient $(\rho)$ are also shown for each configuration

${ }^{a}$ ID univoque configuration is composed of combinations of Forward Speed (FS4, FS6 and FS8 corresponding to 4, 6 and $8 \mathrm{~km} \mathrm{~h}^{-2}$, respectively) and Duty Cycle (DC30, DC50, DC70 and DC100 corresponding to $30,40,50$ and $100 \%$, respectively)

${ }^{\mathrm{b}}$ Statistical significance level: NS $p>0.05 ; * p<0.05 ; * * p<0.01$; $* * * p<0.001$

${ }^{\mathrm{c}}$ Pearson's correlation coeffieient 
(a)

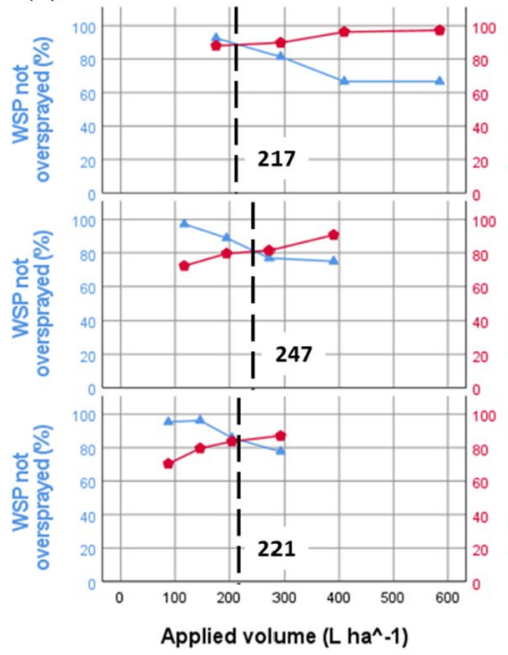

(b)

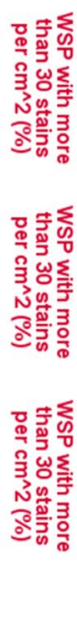

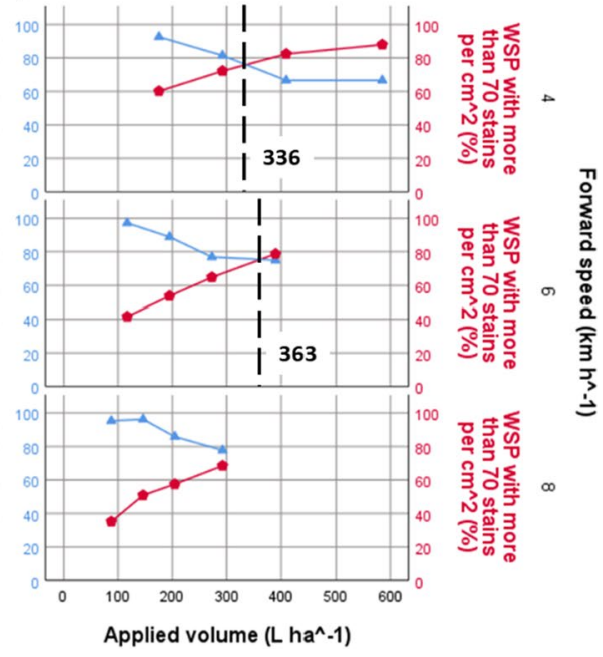

Fig. 11 Dual y-axes charts illustrating the relationships between the percentage of not oversprayed WSP collectors (light-blue triangles-filled) and the percentage of WSP collectors characterized by a deposit density higher than a 30 stains $\mathrm{cm}^{-2}$ for insecticide treatment, or b 70 stains $\mathrm{cm}^{-2}$ for fungicide treatment (red pentagon-filled), with indication of the applied volume $\left(1 \mathrm{ha}^{-1}\right)$, shown separately for the different forward speeds. The vertical dashed black line represents the applied volume at which the curves intersect (Color figure online)

and $3701 \mathrm{ha}^{-1}$ for fungicide treatments. This is in contrast with the current practices adopted by vine farmers as outlined in the OPTIMA survey carried out in 2018, where average spray volumes when applying insecticides were slightly higher than those applying fungicides 370 vs. 317- (Marucco et al., 2019). To obtain an effective spray application able to minimize overspray and to maximize the deposit density needed according to the treatment specifications, the flat fan nozzle XR 8002 operated at different DC and FS gives the farmer a wide range of options to obtain the most adequate volume, especially when insecticides are applied and lower deposit density is required. When the spray application is intended for fungicides, higher FS are not recommended. Indeed, at $8 \mathrm{~km} \mathrm{~h}^{-1}$, the curves do not intersect, meaning that a higher spray volume was needed to obtain an effective treatment. However, when the spray application was operated at $8 \mathrm{~km} \mathrm{~h}^{-1}$ and 100\% DC (FS8_DC100, $292.51 \mathrm{ha}^{-1}$ ) the curves were very close to each other (Fig. 11b). Therefore, if the farmer decides to perform a spray application at $8 \mathrm{~km} \mathrm{~h}^{-1}$ or higher, than nozzles with bigger orifices are recommended. Nevertheless, the proper selection of DC to obtain the defined adequate spray volumes, allowed obtaining less than $25 \%$ of over-sprayed leaves and guaranteed more than $80 \%$ and $75 \%$ of leaves with $\mathrm{N}_{\mathrm{st}}$ higher than 30 and 70 stains $\mathrm{cm}^{-2}$ when insecticide and fungicides are applied, respectively, irrespective of FS (Fig. 11).

\section{Conclusions}

The PWM spray system was demonstrated an effective technology to apply variable rate spray application for precision agriculture in 3D crops like vineyards. It allowed the digital control of flow rate and spray droplet size from agricultural nozzles without concerns for possible under-sprayed canopy zones in the range of $30-100 \%$ duty cycle. 
In particular, from the experimental results it can be concluded that:

(1) Under field-controlled conditions, the on-off effect of the PWM system affects not only the variability of spray coverage measured along the sprayer travel direction, but also along the vertical spray profile. Even if the average spray coverage variability increases with increased forward speed, the magnitude of the duty cycle effect in enhaning the variability increases as the duty cycle decrease from 100 to $30 \%$, irrespective of forward speed.

(2) In contrast, under real field conditions, the on-off effect of the PWM system does not affect the uniformity of spray coverage measured within canopies at different depths and heights, neither did the adopted forward speed show a significant effect. In addition, the applied volume, a combination of different forward speeds and duty cycles, was fully reflected by the differences in both spray coverage and deposit density measured on the upper and lower leaf sides.

(3) Furthermore, the relationships between spray coverage and deposit density allowed identification of the most suitable spray volumes for effective insecticide and fungicide spray applications in order to minimize the overspray and simultaneously maximize the desired deposit density according to the treatment specifications.

In general, the pulsing of the PWM valves has an effect on the spray coverage homogeneity, but this effect was not retrieved under real field conditions, most likely due to the interaction between leaves and sprayer airflow that moves the leaves and carries the spray droplets to the target canopy, and the large variation typical of field applications (e.g. due to the aforementioned air support, canopy density, etc.). Therefore, under real field conditions no concerns about possible under-sprayed canopy zones related to the use of the PWM system were noticed. Furthermore, the use of the PWM system gives farmers a wide range of options to obtain the most adequate spray application rate according to the treatment specifications without changing the spray pressure, and therefore the droplet size spectra produced, with expected benefits in terms of drift reduction.

\section{Appendix}

See Fig. 12 and Tables 6, 7, 8 and 9.

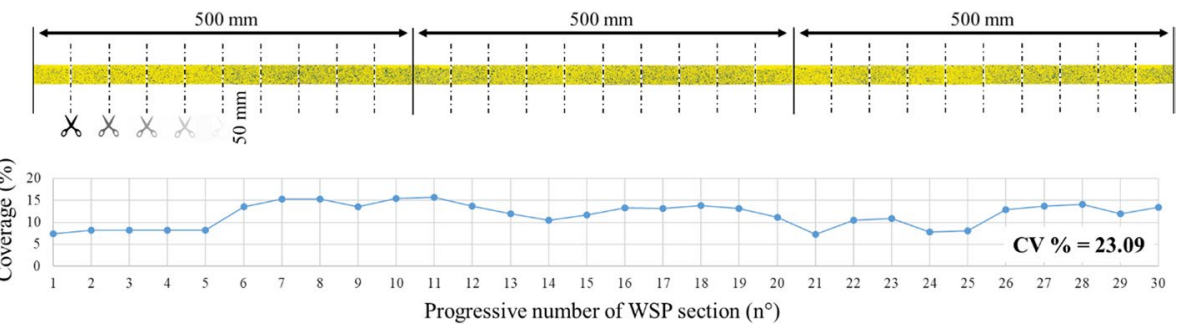

Fig. 12 Example of WSP line composed of three aligned long WSPs $(150 \mathrm{~mm} \times 26 \mathrm{~mm})$ from which 30 WSP sections $(50 \mathrm{~mm} \times 26 \mathrm{~mm})$ were derived. The Coefficient of Variation $(\mathrm{CV}, \%)$ was then calculated within each WSP section for the evaluation of coverage homogeneity 
Table 6 Weather conditions recorded during the trials, split by replicates

\begin{tabular}{|c|c|c|c|c|c|c|c|c|c|}
\hline \multirow{3}{*}{$\begin{array}{l}\text { Config } \& \text { repli- } \\
\text { cates }\end{array}$} & \multicolumn{2}{|c|}{ Temperature } & \multicolumn{2}{|l|}{ RH } & \multicolumn{3}{|c|}{ Wind speed } & \multicolumn{2}{|c|}{ Wind direction } \\
\hline & Mean & $\begin{array}{l}\Delta \mathrm{h} 1- \\
\mathrm{h} 2\end{array}$ & Mean & $\begin{array}{l}\Delta \mathrm{h} 1- \\
\mathrm{h} 2\end{array}$ & Min & $\operatorname{Max}$ & Mean & Dominant & Mean \\
\hline & $\left({ }^{\circ} \mathrm{C}\right)$ & $\left({ }^{\circ} \mathrm{C}\right)$ & $(\%)$ & $(\%)$ & $\left(\mathrm{m} \mathrm{s}^{-1}\right)$ & $\left(\mathrm{m} \mathrm{s}^{-1}\right)$ & $\left(\mathrm{m} \mathrm{s}^{-1}\right)$ & & ( ${ }^{\circ}$ azimuth) \\
\hline \multicolumn{10}{|l|}{ FS4_DC30 } \\
\hline 1 & 18.0 & -0.32 & 73.1 & 0.50 & 0.12 & 3.41 & 1.48 & NNE & 32 \\
\hline 2 & 22.2 & -0.25 & 56.6 & 0.34 & 0.02 & 2.01 & 0.67 & $\mathrm{E}$ & 84 \\
\hline 3 & 22.9 & -0.09 & 63.7 & 0.35 & 0.13 & 3.11 & 1.40 & SSE & 155 \\
\hline \multicolumn{10}{|l|}{ FS4_DC50 } \\
\hline 1 & 18.4 & -0.26 & 60.7 & 0.29 & 0.02 & 2.81 & 0.61 & NNE & 87 \\
\hline 2 & 23.7 & -0.27 & 52.4 & 0.36 & 0.01 & 4.08 & 1.36 & SW & 206 \\
\hline 3 & 22.3 & -0.22 & 65.1 & 0.50 & 0.10 & 2.88 & 0.91 & ESE & 120 \\
\hline \multicolumn{10}{|l|}{ FS4_DC70 } \\
\hline 1 & 19.5 & -0.36 & 66.5 & 0.74 & 0.03 & 2.89 & 1.18 & NW & 9 \\
\hline 2 & 22.6 & -0.26 & 57.0 & 0.55 & 0.01 & 3.37 & 1.02 & SSE & 169 \\
\hline 3 & 25.4 & -0.01 & 51.0 & 0.03 & 0.03 & 2.63 & 0.94 & $\mathrm{E}$ & 83 \\
\hline \multicolumn{10}{|l|}{ FS4_DC100 } \\
\hline 1 & 23.9 & -0.31 & 40.9 & 0.15 & 0.04 & 3.49 & 1.27 & $\mathrm{E}$ & 134 \\
\hline 2 & 25.2 & 0.02 & 41.5 & -0.04 & 0.04 & 3.33 & 1.14 & $\mathrm{~S}$ & 161 \\
\hline 3 & 24.1 & -0.32 & 51.3 & 0.52 & 0.02 & 3.27 & 1.27 & NNE & 51 \\
\hline \multicolumn{10}{|l|}{ FS6_DC30 } \\
\hline 1 & 26.2 & -0.08 & 34.2 & 0.13 & 0.03 & 1.97 & 0.66 & SSE & 34 \\
\hline 2 & 23.4 & -0.38 & 52.5 & 0.52 & 0.05 & 3.03 & 1.33 & NNE & 57 \\
\hline 3 & 23.2 & -0.13 & 61.0 & 0.52 & 0.01 & 2.38 & 1.03 & SSE & 148 \\
\hline \multicolumn{10}{|l|}{ FS6_DC50 } \\
\hline 1 & 20.1 & -0.26 & 52.1 & 0.23 & 0.02 & 1.94 & 0.80 & SSE & 132 \\
\hline 2 & 24.7 & -0.26 & 47.0 & 0.35 & 0.06 & 3.65 & 1.35 & SSE & 179 \\
\hline 3 & 20.7 & -0.16 & 69.4 & 0.31 & 0.11 & 2.29 & 1.10 & SSE & 150 \\
\hline \multicolumn{10}{|l|}{ FS6_DC70 } \\
\hline 1 & 21.0 & -0.37 & 63.0 & 0.86 & 0.01 & 2.23 & 1.03 & NNE & 51 \\
\hline 2 & 19.1 & -0.35 & 68.8 & 0.33 & 0.06 & 1.75 & 0.92 & NW & 3 \\
\hline 3 & 26.9 & -0.29 & 45.9 & 0.46 & 0.04 & 2.62 & 0.96 & $\mathrm{~W}$ & 233 \\
\hline \multicolumn{10}{|l|}{ FS6_DC100 } \\
\hline 1 & 23.2 & -0.22 & 41.7 & 0.25 & 0.08 & 2.97 & 1.05 & SSE & 175 \\
\hline 2 & 25.4 & 0.02 & 40.2 & -0.19 & 0.01 & 2.03 & 0.84 & SSE & 136 \\
\hline 3 & 25.8 & -0.14 & 49.0 & 0.11 & 0.07 & 3.32 & 1.34 & ESE & 135 \\
\hline \multicolumn{10}{|l|}{ FS8_DC30 } \\
\hline 1 & 16.8 & -0.12 & 82.1 & 0.13 & 0.02 & 2.11 & 0.91 & NNE & 354 \\
\hline 2 & 25.3 & 0.04 & 40.7 & -0.38 & 0.08 & 2.09 & 0.90 & ESE & 147 \\
\hline 3 & 23.0 & -0.10 & 62.9 & 0.32 & 0.18 & 2.71 & 1.24 & SSE & 147 \\
\hline \multicolumn{10}{|l|}{ FS8_DC50 } \\
\hline 1 & 21.1 & -0.18 & 44.6 & 0.22 & 0.01 & 2.39 & 1.02 & $\mathrm{~S}$ & 173 \\
\hline 2 & 24.8 & -0.18 & 44.8 & 0.03 & 0.04 & 2.86 & 1.00 & $\mathrm{~S}$ & 187 \\
\hline 3 & 20.9 & -0.12 & 68.3 & 0.27 & 0.03 & 1.92 & 0.83 & SSE & 156 \\
\hline FS8_DC70 & & & & & & & & & \\
\hline
\end{tabular}


Table 6 (continued)

\begin{tabular}{|c|c|c|c|c|c|c|c|c|c|}
\hline \multirow{3}{*}{$\begin{array}{l}\text { Config }{ }^{a} \& \text { repli- } \\
\text { cates }\end{array}$} & \multicolumn{2}{|c|}{ Temperature } & \multicolumn{2}{|l|}{ RH } & \multicolumn{3}{|c|}{ Wind speed } & \multicolumn{2}{|c|}{ Wind direction } \\
\hline & Mean & $\begin{array}{l}\Delta \text { h1- } \\
\text { h2 }\end{array}$ & Mean & $\begin{array}{l}\Delta \text { h1- } \\
\text { h2 }\end{array}$ & Min & Max & Mean & Dominant & Mean \\
\hline & $\left({ }^{\circ} \mathrm{C}\right)$ & $\left({ }^{\circ} \mathrm{C}\right)$ & $(\%)$ & $(\%)$ & $\left(\mathrm{m} \mathrm{s}^{-1}\right)$ & $\left(\mathrm{m} \mathrm{s}^{-1}\right)$ & $\left(\mathrm{m} \mathrm{s}^{-1}\right)$ & & ( ${ }^{\circ}$ azimuth $)$ \\
\hline 1 & 21.7 & -0.26 & 60.5 & 0.46 & 0.13 & 2.93 & 1.26 & $\mathrm{~S}$ & 163 \\
\hline 2 & 20.7 & -0.44 & 65.2 & 1.02 & 0.02 & 1.87 & 0.89 & ENE & 60 \\
\hline 3 & 27.0 & -0.26 & 46.6 & 0.59 & 0.07 & 2.79 & 0.95 & SSE & 56 \\
\hline \multicolumn{10}{|l|}{ FS8_DC100 } \\
\hline 1 & 22.1 & -0.23 & 46.5 & 0.27 & 0.14 & 3.01 & 1.29 & $\mathrm{~S}$ & 149 \\
\hline 2 & 24.9 & -0.12 & 43.0 & -0.11 & 0.01 & 2.01 & 0.90 & $\mathrm{E}$ & 103 \\
\hline 3 & 24.7 & -0.27 & 51.6 & 0.61 & 0.06 & 3.53 & 1.42 & ENE & 70 \\
\hline
\end{tabular}

${ }^{a}$ ID univoque configuration is composed of combinations of Forward Speed (FS4, FS6 and FS8 corresponding to 4,6 and $8 \mathrm{~km} \mathrm{~h}^{-1}$, respectively) and Duty Cycle (DC30,DC50, DC70 and DC100 corresponding to $30,40,50$ and $100 \%$, respectively)

Table 7 Mean spray coverage (SC, \%) and standard deviation of the mean $(\sigma)$ obtained from the combination of forward speed and duty cycle, for the WSP lines placed at different sampling positions

\begin{tabular}{|c|c|c|c|c|c|}
\hline \multirow{3}{*}{$\begin{array}{l}\text { Forward speed } \\
\left(\mathrm{m} \mathrm{s}^{-1}\right)\end{array}$} & \multirow{3}{*}{$\begin{array}{l}\text { WSP line } \\
\text { position }^{a}\end{array}$} & \multicolumn{3}{|c|}{ Duty cycle $(\%)$} & \multirow{3}{*}{$\begin{array}{l}100 \\
\mathrm{SC}(\%) \pm \sigma\end{array}$} \\
\hline & & 30 & 50 & 70 & \\
\hline & & $\mathrm{SC}(\%) \pm \sigma$ & $\mathrm{SC}(\%) \pm \sigma$ & $\mathrm{SC}(\%) \pm \sigma$ & \\
\hline \multicolumn{6}{|c|}{ Horizontal WSP lines } \\
\hline 1.11 & $\mathrm{H} 1$ & $55.1 \pm 7.8$ & $74.5 \pm 12$ & $78.7 \pm 4.8$ & $87.2 \pm 7.2$ \\
\hline 1.11 & $\mathrm{H} 2$ & $69.5 \pm 9.0$ & $82.6 \pm 5.6$ & $84.4 \pm 6.8$ & $86.8 \pm 6.2$ \\
\hline 1.11 & H3 & $11.7 \pm 6.2$ & $17.4 \pm 6.4$ & $23.7 \pm 7.9$ & $27.2 \pm 7.4$ \\
\hline 1.67 & H1 & $38.6 \pm 6.8$ & $49.1 \pm 10.5$ & $65.5 \pm 6.2$ & $69 \pm 7.1$ \\
\hline 1.67 & $\mathrm{H} 2$ & $46.5 \pm 5.7$ & $60.5 \pm 15.4$ & $76.4 \pm 7.2$ & $74.4 \pm 7.0$ \\
\hline 1.67 & $\mathrm{H} 3$ & $7.3 \pm 2.9$ & $9.9 \pm 4.8$ & $16.2 \pm 5.8$ & $16.6 \pm 6.5$ \\
\hline 2.22 & H1 & $28.4 \pm 6.9$ & $39.6 \pm 10.4$ & $49.4 \pm 6.8$ & $57.1 \pm 7.6$ \\
\hline 2.22 & $\mathrm{H} 2$ & $38.6 \pm 10.4$ & $50.5 \pm 12.6$ & $63.7 \pm 8.7$ & $65.4 \pm 7.8$ \\
\hline 2.22 & $\mathrm{H} 3$ & $6.6 \pm 4.3$ & $7.4 \pm 2.9$ & $11.9 \pm 4.4$ & $14.5 \pm 5.0$ \\
\hline \multicolumn{6}{|c|}{ Vertical WSP lines } \\
\hline 1.11 & D1 & $43.8 \pm 16.7$ & $61.9 \pm 18.6$ & $69.1 \pm 20.1$ & $76.7 \pm 17.0$ \\
\hline 1.11 & D2 & $44.5 \pm 16.5$ & $57.2 \pm 19.7$ & $70.4 \pm 18.7$ & $75.1 \pm 16.0$ \\
\hline 1.11 & D3 & $43.9 \pm 16.5$ & $60.1 \pm 21.6$ & $68.2 \pm 19.7$ & $74.3 \pm 19.0$ \\
\hline 1.67 & D1 & $30.6 \pm 12.9$ & $41.5 \pm 15.9$ & $57.2 \pm 18.4$ & $58.1 \pm 19.6$ \\
\hline 1.67 & D2 & $30.6 \pm 12.2$ & $40.9 \pm 15.3$ & $52.6 \pm 17.1$ & $56.6 \pm 17.2$ \\
\hline 1.67 & D3 & $27.4 \pm 11.3$ & $40.8 \pm 16.5$ & $53.8 \pm 19.8$ & $58.2 \pm 18.4$ \\
\hline 2.22 & D1 & $24 \pm 10.1$ & $31.7 \pm 14.6$ & $41.4 \pm 14.8$ & $48.1 \pm 16.5$ \\
\hline 2.22 & D2 & $23.6 \pm 9.5$ & $30.1 \pm 12.8$ & $41.9 \pm 14.4$ & $46 \pm 17.2$ \\
\hline 2.22 & D3 & $21.8 \pm 9.6$ & $29.4 \pm 14.4$ & $40 \pm 14.3$ & $48.1 \pm 17.4$ \\
\hline
\end{tabular}

${ }^{\mathrm{a}} \mathrm{H} 1=0.8 \mathrm{~m}, \mathrm{H} 2=1.4 \mathrm{~m}$ and $\mathrm{H} 3=2.0 \mathrm{~m}$ above the ground; $\mathrm{D} 1=0 \mathrm{~m}, \mathrm{D} 2=1 \mathrm{~m}$ and D3 $=2 \mathrm{~m}$ along advancing distance 
Table 8 Mean spray coverage (SC, \%), averaged over upper and lower leaf sides, and standard deviation of the mean $(\sigma)$ obtained from the combination of forward speed and duty cycle, for the short WSP placed at different canopy depth and height positions

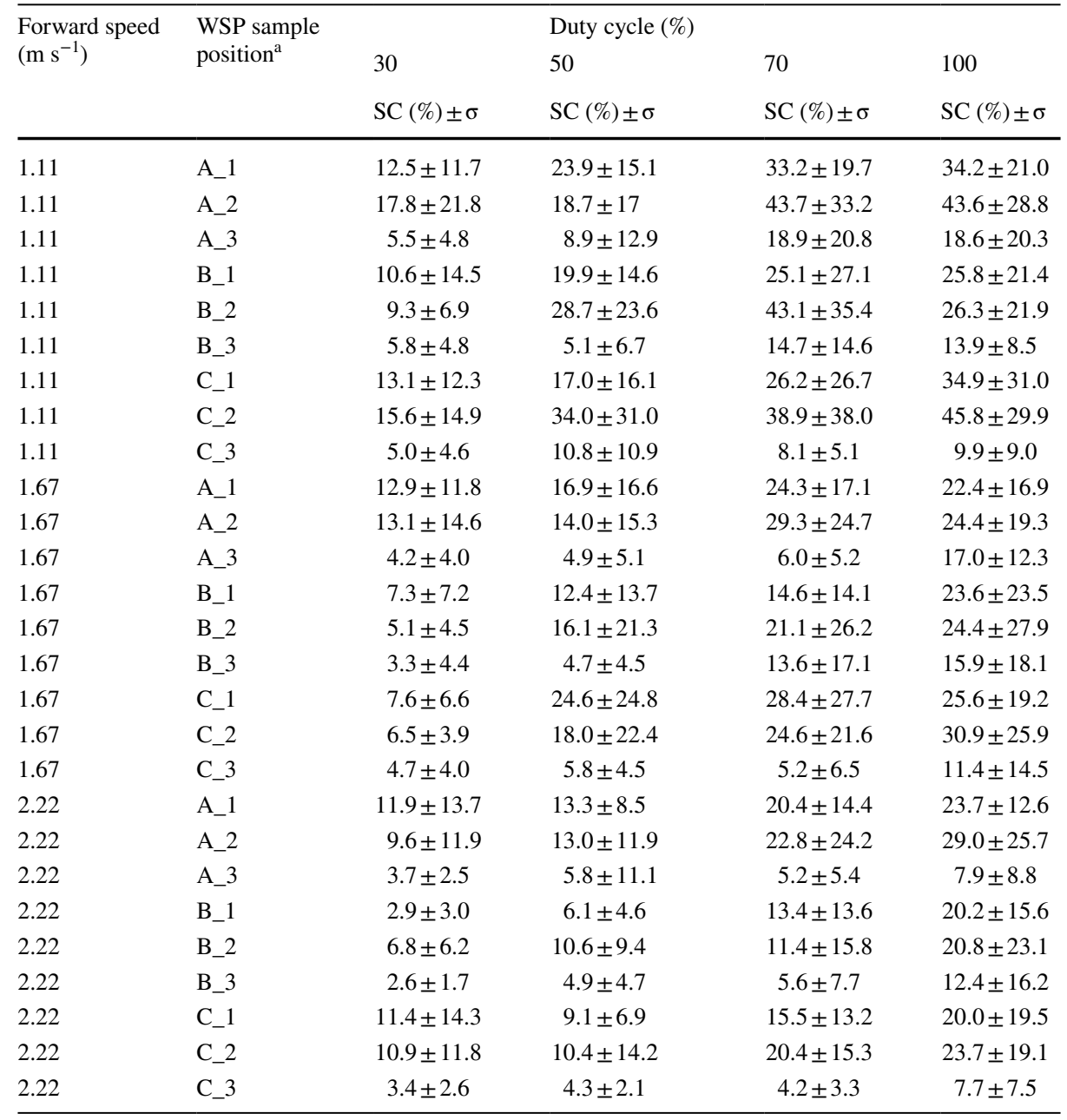

${ }^{a}$ Nine sampling positions arranged at three depths $(\mathrm{A}=$ right edge, $\mathrm{B}=$ middle, $\mathrm{C}=$ left edge $)$ and three heights $(1=$ bottom, $2=$ middle, $3=$ top $)$ 


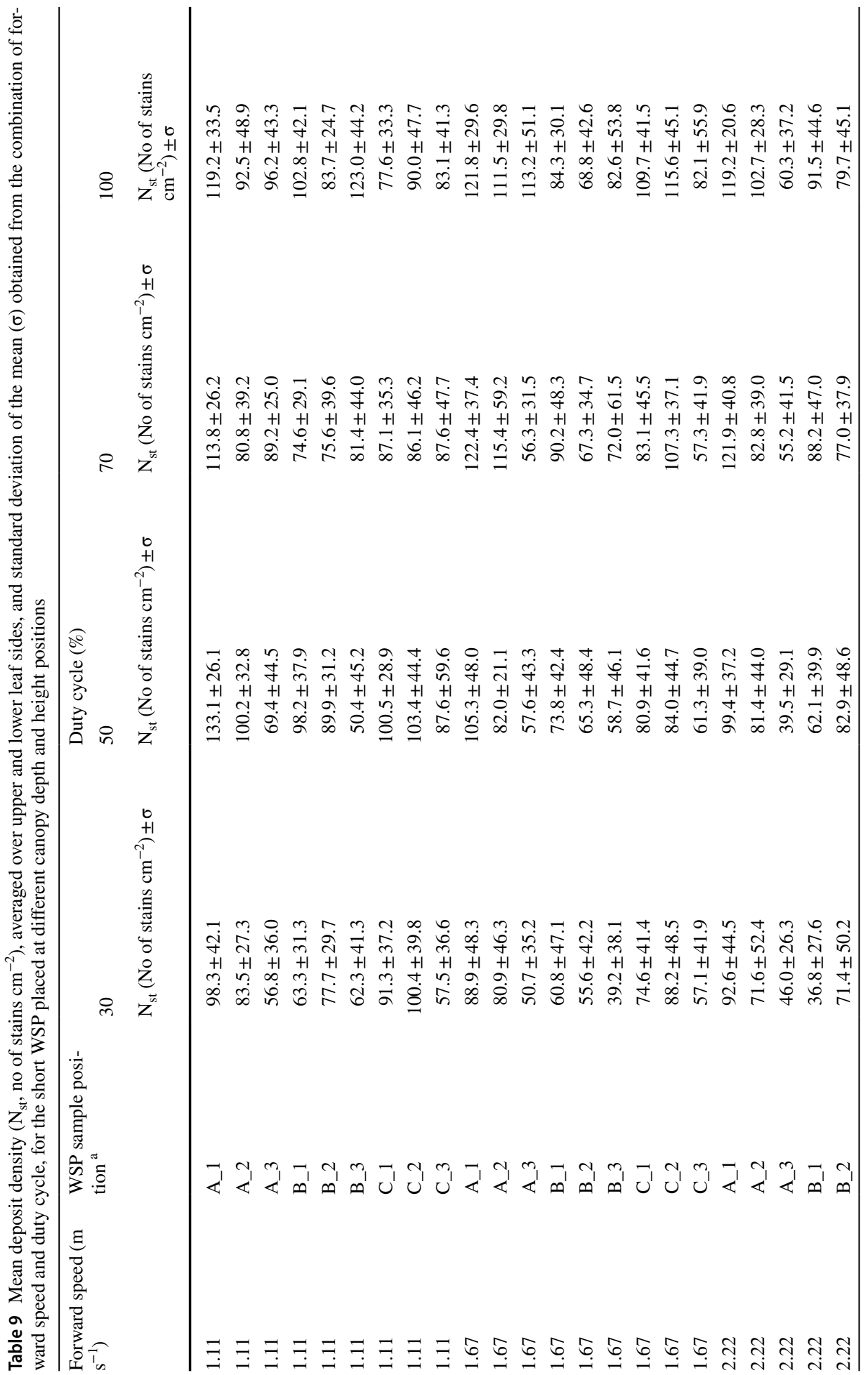




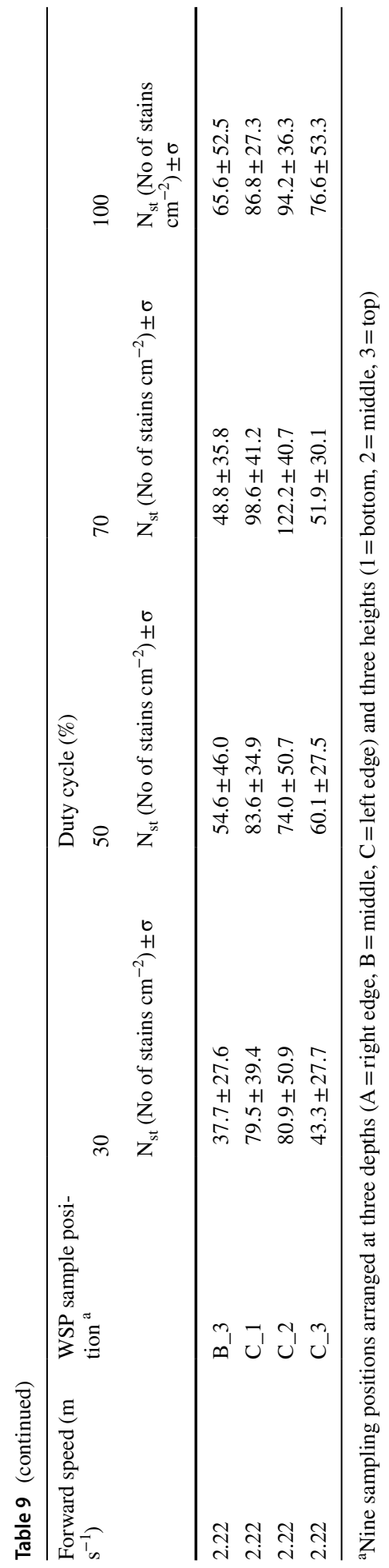


Acknowledgements The authors would like to thank Davide Allochis for the help provided during field experimental activities. The authors would also like to thank Caffini S.p.a., TeeJet Technologies and KEB automation KG for the technical support provided in this research.

Funding Open access funding provided by Università degli Studi di Torino within the CRUI-CARE Agreement. This research is supported by European Union's Horizon 2020 research and innovation programme (Call: H2020-SFS-2016-2017; Sustainable Food Security-Resilient and resource-efficient value chains) under grant agreement No 773718, project OPTIMA (OPTimised Integrated pest MAnagement for precise detection and control of plant diseases in perennial crops and open-field vegetables). http://optima-h2020. $\mathrm{eu} /$

\section{Declarations}

Conflict of interest The authors declare that they have no known competing financial interests or personal relationships that could have appeared to influence the work reported in this paper.

Open Access This article is licensed under a Creative Commons Attribution 4.0 International License, which permits use, sharing, adaptation, distribution and reproduction in any medium or format, as long as you give appropriate credit to the original author(s) and the source, provide a link to the Creative Commons licence, and indicate if changes were made. The images or other third party material in this article are included in the article's Creative Commons licence, unless indicated otherwise in a credit line to the material. If material is not included in the article's Creative Commons licence and your intended use is not permitted by statutory regulation or exceeds the permitted use, you will need to obtain permission directly from the copyright holder. To view a copy of this licence, visit http://creativecommons.org/licenses/by/4.0/.

\section{References}

Anglund, E. A., \& Ayers, P. D. (2003). Field evaluation of response times for a variable rate (pressure-based and injection) liquid chemical applicator. Applied Engineering in Agriculture, 19(3), 273-282.

Balsari, P., Marucco, P., \& Tamagnone, M. (2009). A crop identification system (CIS) to optimise pesticide applications in orchards. Journal of Horticultural Science \& Biotechnology, 84, 113-116.

Berk, P., Hocevar, M., Stajnko, D., \& Belsak, A. (2016). Development of alternative plant protection product application techniques in orchards, based on measurement sensing systems: A review. Computers and Electronics in Agriculture, 124, 273-288.

Barua, D. K. (2005). Beaufort wind scale. In M. L. Schwartz (Ed.), Encyclopedia of coastal science. Encyclopedia of earth science series. Springer.

Butts, T., Butts, L. E., Luck, J. D., Fritz, B. K., Hoffman, W. C., \& Kruger, G. R. (2019). Droplet size and nozzle tip pressure from a pulse-width modulation sprayer. Biosystems Engineering, 178, 52-62.

Butts, T., Hoffmann, W., Luck, J., \& Kruger, G. (2018). Droplet velocity from broadcast agricultural nozzles as influenced by pulse-width modulation. In Pesticide Formulation and Delivery Systems: 38th Volume, Innovative Application, Formulation, and Adjuvant Technologies: ASTM International. https:// doi.org/10.1520/STP161020170192

Cai, J., Wang, X., Gao, Y., Yang, S., \& Zhao, C. (2019). Design and performance evaluation of a variablerate orchard sprayer based on a laser-scanning sensor. International Journal of Agricultural and Biological Engineering, 12(6), 51-57.

Campos, J., Gallart, M., Llop, J., Ortega, P., Salcedo, R., \& Gil, E. (2020). On-farm evaluation of prescription map-based variable rate application of pesticides in vineyards. Agronomy, 10(1), 102.

Cerruto, E. (2007). Influence of airflow rate and forward speed on the spray deposit in vineyards. Journal of Agricultural Engineering, 1, 7-14.

Cerruto, E., Manetto, G., Longo, D., Failla, S., \& Papa, R. (2019). A model to estimate the spray deposit by simulated water sensitive papers. Crop Protection, 124, 104861.

Chen, L., Wallhead, M., Zhu, H., \& Fulcher, A. (2019). Control of insects and diseases with intelligent variable-rate sprayers in ornamental nurseries. Journal of Environmental Horticulture, 37(3), 90-100.

Chen, Y., Ozkan, E., Zhu, H., Derksen, R., \& Krause, C. (2013). Spray deposition inside tree canopies from a newly developed variable-rate air-assisted sprayer. Transactions of the ASABE, 56(6), 1263-1272. 
Comba, L., Biglia, A., Ricauda Aimonino, D., Barge, P., Tortia, C., \& Gay, P. (2019). 2D and 3D data fusion for crop monitoring in precision agriculture. In Proceedings of MetroAgriFor 2019-2019 IEEE International Workshop on Metrology for Agriculture and Forestry, pp. 62-67, 8909219.

Deng, W., Yanbo, H., Zhao, C., Wang, X., \& Liu, J. (2013). Spatial distribution visualization of PWM continuous variable-rate spray. International Journal of Agricultural and Biological Engineering, 6(4), $1-8$.

Deng, W., Zhao, C., \& Zhou, J. (2020). Comparison and evaluation of spray characteristics of three types of variable-rate spray. In Proceedings of Virtual ICPA -International Conference on Precision Agriculture-2020. Retrieved January 8, 2021, from https://www.ispag.org/abstract_papers/papers/abstract_ 1087.pdf

Duga, A. T., Ruysen, K., Dekeyser, D., Nuyttens, D., Bylemans, D., Nicolai, B. M., et al. (2015). Spray deposition profiles in pome fruit trees: Effects of sprayer design, training system and tree canopy characteristics. Crop Protection, 67, 200-213. https://doi.org/10.1016/j.cropro.2014.10.016

EC. (2020). European Commission-Farm to Fork Strategy-for a fair, healthy and environmentallyfriendly food system. Retrieved December 22, 2020, from https://ec.europa.eu/food/farm2fork_en

Fox, R. D., Derksen, R. C., Cooper, J. A., Krause, C. R., \& Ozkan, H. E. (2003). Visual image system measurements of spray deposits using water-sensitive paper. Transactions of the ASAE, 19, 549-552.

Garcerá, C., Moltó, E., \& Chueca, P. (2011). Effect of spray volume of two organophosphate pesticides on coverage and on mortality of California red scale Aonidiella aurantii (Maskell). Crop Protection, 30(6), 693-697.

Gil, E., Escola, A., Rosell, J. R., Planas, S., \& Val, L. (2007). Variable rate application of plant protection products in vineyard using ultrasonic sensors. Crop Protection, 26(8), 1287-1297.

Giles, D. K. (2020). Pulse width modulation for nozzle flow control: Principles, development and status of the technology. Aspects of Applied Biology, 144, 59-66.

Giles, D. K., \& Ben-Salem, E. (1992). Spray droplet velocity and energy in intermittent flow from hydraulic nozzles. Journal of Agricultural Engineering Research, 51, 101-112.

Giles, D. K., \& Comino, J. A. (1989). Variable flow control for pressure atomization nozzles. SAE Transactions, 98(2), 237-249.

Giles, D. K., \& Comino, J. A. (1990). Droplet size and spray pattern characteristics of an electronic flow controller for spray nozzles. Journal of Agricultural Engineering Research, 47, 249-267.

Giles, D. K., Andersen, P. G., \& Nilars, M. (2002). Flow control and spray cloud dynamics from hydraulic atomizers. Transactions of the ASAE, 45(3), 539-546.

Gopala Pillai, S., Tian, L., \& Zheng, J. (1999). Evaluation of a flow control system for site-specific herbicide applications. Transactions of the ASAE, 42(4), 863-870.

Grella, M., Marucco, P., \& Balsari, P. (2019). Toward a new method to classify the airblast sprayer according to their potential drift reduction: Comparison of direct and new indirect measurements methods. Pest Management Science, 75, 2219-2235. https://doi.org/10.1002/ps.5354

Grella, M., Miranda-Fuentes, A., Marucco, P., \& Balsari, P. (2020). Field assessment of a newly-designed pneumatic spout to contain spray drift in vineyards: Evaluation of canopy distribution and off-target losses. Pest Management Science, 76(12), 4173-4191. https://doi.org/10.1002/ps.5975

Hołownicki, R., Doruchowski, G., Swiechowski, W., \& Jaeken, P. (2002). Methods of evaluation of spray deposit and coverage on artificial targets. Electronic Journal of Polish Agricultural Universities, 5(1), \#03. http://www.ejpau.media.pl/volume5/issue1/engineering/art-03.html [Accessed 14th December 2020]

Jeon, H. Y., \& Zhu, H. (2012). Development of a variable-rate sprayer for nursery liner applications. Transactions of the ASABE, 55(1), 303-312.

Jiang, H., Zhang, L., \& Shi, W. (2016). Effects of operating parameters for dynamic PWM variable spray system on spray distribution uniformity. IFAC-Papers OnLine, 49(16), 216-220.

Li, J., Li, Z. Q., Ma, Y. K., Cui, H. J., Yang, Z., \& Lu, H. Z. (2021). Effects of leaf response velocity on spray deposition with an air-assisted orchard sprayer. International Journal of Agricultural and Biological Engineering, 14(1), 123-132. https://doi.org/10.25165/j.ijabe.20211401.5435

Llorens, J., \& Hewitt, A. (2019). Droplet size effect in a PWM system: first results to improve orchard spray application. In Proceedings of SUPROFRUIT 2019-15th Workshop on Spray Application and Precision Technology in Fruit Growing, 16-18 July 2019, East Malling-UK, (pp. 55-56). NIAB EMR. Retrieved July 15, 2021, from https://edepot.wur.nl/494871

Lorenz, D., Eichorn, D., Bleiholder, H., Klose, R., Meier, U., \& Weber, E. (1994). Phänologische Entwicklungsstadien der Weinrebe (Vitis vinifera L. ssp. vinifera). Codierung und Beschreibung nach der erweiterten BBCH-Skala [Phenological stages of development of the grapevine (Vitis vinifera L. ssp. Vinifera). Coding and description according to the expanded BBCH scale]. Viticulture and Enology Sciences, 49, 66-70. https://doi.org/10.1111/j.1755-0238.1995.tb00085.x 
Llorens, J., Gil, E., Llop, J., \& Escola, A. (2010). Variable rate dosing in precision viticulture: Use of electronic devices to improve application efficiency. Crop Protection, 29(3), 239-248. https://doi.org/10.1016/j.cropro.2009.12.022

Mangus, D. L., Sharda, A., Engelhardt, A., Flippo, D., Strasser, R., Luck, J. D., et al. (2017). Analyzing the nozzle spray fan pattern of an agricultural sprayer using pulse width modulation technology to generate an on-ground coverage map. Transactions of the ASABE, 60(2), 315-325.

Marucco, P., Balsari, P., Grella, M., Pugliese, M., Eberle, D., Gil Moya, E., et al. (2019). OPTIMA EU project: Main goal and first results of inventory of current spray practices in vineyards and orchards. In Proceedings of SUPROFRUIT 2019-15th Workshop on Spray Application and Precision Technology in Fruit Growing, 16-18 July 2019, East Malling-UK, (pp. 99-100). NIAB EMR. Retrieved July 15, 2021, from https://edepot.wur.nl/494871

Miranda-Fuentes, A., Llorens, J., Rodriguez-Lizana, A., Cuenca, A., Gil, E., Blanco-Roldan, G. L., et al. (2016). Assessing the optimal liquid volume to be sprayed on isolated olive trees according to their canopy volumes. Science of the Total Environment, 568, 296-305. https://doi.org/10.1016/j.scitotenv.2016. 06.013

Miranda-Fuentes, A., Rodríguez-Lizana, A., Gil, E., Agüera-Vega, J., \& Gil-Ribes, J. A. (2015). Influence of liquid-volume and airflow rates on spray application quality and homogeneity in super-intensive olive tree canopies. Science of the Total Environment, 537, 250-259.

Nuyttens, D., Baetens, K., De Schampheleire, M., \& Sonck, B. (2007). Effect of nozzle type, size and pressure on spray droplet characteristics. Biosystems Engineering, 97(3), 333-345.

Palleja, T., \& Landers, A. (2015). Real time canopy density estimation using ultrasonic envelope signals in the orchard and vineyard. Computers and Electronics in Agriculture, 115, 108-117.

Pergher, G., \& Petris, R. (2008). The effect of air flow rate on spray deposition in a Guyot trained vineyard. Agricultural Engineering International: the CIGR Ejournal. https://doi.org/10.13140/2.1.1488.4480

Pierce, R. A., \& Ayers, P. D. (2001). Evaluation of deposition and application accuracy of a pulse width modulation variable rate field sprayer. ASAE Meeting Paper No. 1-1077. ASAE.

Rincón, V. J., Grella, M., Marucco, P., Eloi Alcatrão, L., Sanchez-Hermosilla, J., \& Balsari, P. (2020). Spray performance assessment of a remote-controlled vehicle prototype for pesticide application in greenhouse tomato crops. Science of the Total Environment, 726, 138509. https://doi.org/10.1016/j.scitotenv.2020. 138509

Rueden, C. T., Schindelin, J., Hiner, M. C., De Zonia, B. E., Walter, A. E., Arena, E. T., et al. (2017). Image J2: ImageJ for the next generation of scientific image data. BMC Bioinformatics, 18(529), 1-26. https://doi. org/10.1186/s12859-017-1934-Z

Salcedo, R., Zhu, H., Zhang, Z., Wei, Z., Chen, L., Ozkan, E., et al. (2020). Foliar deposition and coverage on young apple trees with PWM-controlled spray systems. Computers and Electronics in Agriculture, 178, 105794.

Salyani, M., Zhu, H., Sweeb, R. D., \& Pai, N. (2013). Assessment of spray distribution with water-sensitive paper. Agricultural Engineering International: CIGR Journal, 15(2), 101-111.

Świechowski, W., Doruchowski, G., Hołownicki, R., \& Godyń, A. (2004). Penetration of air within the apple tree canopy as affected by the aur jet characterisitics and travel velocity of the sprayer. Electronic Journal of Polish Agricultural Universities, 7(2), \#03. Retrieved February 2, 2021, from http://www.ejpau.media. $\mathrm{pl}$ /volume7/issue2/engineering/art-03.html

TOPPS-Prowadis Project. (2014). Best management practices to reduce spray drift. Retrieved January 18 , 2021, from http://www.topps-life.org/

Vitali, M., Tamagnone, M., La Iacona, T., \& Lovisolo, C. (2013). Measurement of grapevine canopy leaf area by using an ultrasonic-based method. Journal International Des Sciences De La Vigne Et Du Vin, 47, 183-189. https://doi.org/10.20870/oenoone.2013.47.3.1553

Wei, Z., Zhu, H., Zhang, Z., Salcedo, R., \& Duan, D. (2020). Droplet size spectrum, activation pressure and flow rate discharged from PWM flat-fan nozzles. Transactions of the ASABE, 64(1), 313-325. https://doi. org/10.13031/trans.14100

Zhang, Z., Wang, X., Lai, Q., \& Zhang, Z. (2018). Review of variable-rate sprayer applications based on realtime sensor technologies. In S. Hussmann (Ed.), Automation in agriculture-Securing food supplies for for future generations (pp. 53-79). IntechOpen. https://doi.org/10.5772/intechopen.73622

Zhu, H., Salyani, M., \& Fox, R. D. (2011). A portable scanning system for evaluation of spray deposit distribution. Computers and Electronics in Agriculture, 76, 38-43.

Zhu, H., Zondag, R. H., Derksen, R. C., Reding, M., \& Krause, C. R. (2008). Influence of spray volume on spray deposition and coverage within nursery trees. Journal of Environmental Horticulture, 26(1), 51-57.

Publisher's Note Springer Nature remains neutral with regard to jurisdictional claims in published maps and institutional affiliations. 


\section{Authors and Affiliations}

\section{Marco Grella ${ }^{1}$ (D) $\cdot$ Fabrizio Gioelli ${ }^{1} \cdot$ Paolo Marucco ${ }^{1} \cdot$ Ingrid Zwertvaegher $^{2}$. Eric Mozzanini ${ }^{1} \cdot$ Nikolaos Mylonas $^{3} \cdot$ David Nuyttens $^{2} \cdot$ Paolo Balsari $^{1}$}

Fabrizio Gioelli

fabrizio.gioelli@unito.it

Paolo Marucco

paolo.marucco@unito.it

Ingrid Zwertvaegher

Ingrid.Zwertvaegher@ilvo.vlaanderen.be

Eric Mozzanini

eric.mozzanini@unito.it

Nikolaos Mylonas

nmylonas@aua.gr

David Nuyttens

David.Nuyttens@ilvo.vlaanderen.be

Paolo Balsari

paolo.balsari@unito.it

1 Department of Agricultural, Forest and Food Sciences (DiSAFA), University of Turin (UNITO), Largo Paolo Braccini, 2, 10095 Grugliasco, TO, Italy

2 Flanders Research Institute for Agriculture, Fisheries and Food (ILVO), Burgemeester Van Gansberghelaan 115, Box 1, 9820 Merelbeke, Belgium

3 Agricultural University of Athens, Iera Odos 75, 11845 Athens, Greece 